\title{
Thermal Behavior, Reaction Pathways and Kinetic Implications of using a Ni/SiO2 Catalyst for Waste Tire Pyrolysis
}

Paula Osorio-Vargas ( $\sim$ posorio@ubiobio.cl)

Universidad del Bio Bio

lleana D. Lick

Universidad Nacional de la Plata

Felipe Sobrevía

Universidad del Bio Bio

Daniela Correa-Muriel

Universidad Tecnologica de Pereira

Tamara Menares

Universidad del Bio Bio

Raydel Manrique

Universidad del Bio Bio

Monica L. Casella

Universidad Nacional de la Plata

Luis E. Arteaga-Pérez

Universidad del Bio Bio

\section{Research Article}

Keywords: catalytic waste tire pyrolysis, Ni/SiO2, Py-GC/MS, isoconversional methods, Master-plots method, TGA/FTIR

Posted Date: May 28th, 2021

DOl: https://doi.org/10.21203/rs.3.rs-232987/v1

License: (c) (i) This work is licensed under a Creative Commons Attribution 4.0 International License.

Read Full License 
Thermal behavior, reaction pathways and kinetic implications of using a $\mathrm{Ni} / \mathrm{SiO}_{2}$ catalyst for waste tire pyrolysis

Paula Osorio-Vargas ${ }^{1 *}$, Ileana D. Lick ${ }^{2}$, Felipe Sobrevía ${ }^{1}$, Daniela Correa-Muriel ${ }^{3}$, Tamara Menares ${ }^{1,4}$, Raydel Manrique $^{1}$, Monica L. Casella ${ }^{2}$, Luis E. Arteaga-Pérez ${ }^{1,5^{* *}}$

${ }^{1}$ Laboratory of Thermal and Catalytic Processes (LPTC-UBB), Wood Engineering Department, Universidad del Bio-Bio, Concepción, Chile

${ }^{2}$ CINDECA (CCT La Plata-CONICET, UNLP), Universidad Nacional de La Plata, Facultad de Ciencias Exactas, 47 N॰257, 1900 La Plata, Argentina

${ }^{3}$ Grupo de investigación en Fotocatálisis y Estado Sólido, Facultad de Tecnología, Escuela de Química, Universidad Tecnológica de Pereira, Pereira, Colombia.

${ }^{4}$ Thermochemical Conversion of Biomass Research Group, Department of Green Chemistry and Technology, Faculty of Bioscience Engineering, Gent University, 653, Coupure Links, 9000, Gent, Belgium ${ }^{5}$ Universidad de Concepción, Unidad de Desarrollo Tecnológico, Coronel, Chile.

*Corresponding authors:

Paula Osorio-Vargas

Universidad del Bio Bio, Escuela de Ingeniería Química, Chile

Tel: (+5641) 3111161

e-mail: posorio@ubiobio.cl

Luis E. Arteaga-Pérez

Universidad del Bio Bio, Escuela de Ingeniería Química, Chile

Tel: (+5641) 3111691

e-mail: larteaga@ubiobio.cl 


\section{Abstract}

Catalytic pyrolysis has been used to upgrading the quality of pyrolytic liquids. Herein, we report a comprehensive study on the catalytic pyrolysis of waste tires using $\mathrm{Ni} / \mathrm{SiO}_{2}$ as catalysts. The analyses were carried out by combining thermogravimetry (TGA), TGA interfaced to a Fourier Transform Infrared spectrometer (TGA-FTIR), and pyrolysis coupled to gas chromatography/mass spectrometer (Py-GC/MS) techniques. During waste tire decomposition, the main functional groups detected in the FTIR were alkenes, aromatics, and heteroatoms-containing groups such as nitrogen, sulfur, and oxygen. Meanwhile, by Py-GC/MS were identified mainly D,L-limonene, isoprene, benzene, toluene, xylenes (BTX), and p-cymene. The PyGC/MS experiments at three different temperatures $\left(350,400\right.$, and $\left.450{ }^{\circ} \mathrm{C}\right)$ suggested an effect of the catalyst on product distribution. The Ni catalyst promoted cyclization reactions and subsequently aromatization, leading to an improved vapors composition. The use of iso-conversional kinetic models along with master plots allows proposing a multiple-step reaction mechanism, which was well described by the Avrami-Erofeev, Random Scission, and truncated Sestak-Berggren models. The values of activation energies show differences for the catalyzed and uncatalyzed pyrolysis $\left(111.0 \mathrm{~kJ} \mathrm{~mol}^{-1}\right.$ and $\left.168.4 \mathrm{~kJ} \mathrm{~mol}^{-1}\right)$, validating the effectivity of $\mathrm{Ni} / \mathrm{SiO}$. Finally, the thermal Biot $(>1)$ and $\mathrm{Py}^{\mathrm{I}}$ and $\mathrm{Py}$ II numbers $\left(10^{-3}<\mathrm{Py}^{\mathrm{I}}<10^{-1}\right.$ and $\left.10^{-2}<\mathrm{Py}^{\mathrm{II}}<10^{-3}\right)$ confirms that the process is being occurred between the kinetic and the convection-limited regimes.

Keywords: catalytic waste tire pyrolysis, $\mathrm{Ni} / \mathrm{SiO}_{2}, \mathrm{Py}-\mathrm{GC} / \mathrm{MS}$, isoconversional methods, Master-plots method, TGA/FTIR 


\section{Introduction}

Every year around 25.7 million tons of tires are wasted worldwide, and only $65 \%$ of them undergo some form of recycling or recovery [1]. After their useful life, the handling and disposal of tires involve several technical and environmental challenges, mostly related to the huge quantities generated yearly and to their complex polymeric composition. Most of the tire formulations are constituted by a blend of natural rubber (cis-1,4-polyisoprene: NR) and synthetic rubbers such as styrene-butadiene (SBR) and/or polybutadiene (BR) alongside a set of substances including vulcanizing agents, accelerators, aging retardants, and reinforced fillers as carbon black; this latter provides black pigmentation, resilience, and abrasion resistance [2]. This chemical richness is one of the drivers for seeking more convenient solutions for valorizing the tires into marketable products within a circular economy cycle. In this endeavor, thermal treatment via pyrolysis has emerged as an alternative to current practices viz incineration and landfills [3].

Pyrolysis is a thermal process carried out at temperatures ranging from $350^{\circ} \mathrm{C}$ to $700^{\circ} \mathrm{C}$, under a low-oxidizing or inert atmosphere. When waste tires (WT) are transformed via pyrolysis, the original polymer mixture decomposes into three fractions: a solid (recovered carbon black, rCB), a multicomponent liquid mixture (tire pyrolytic oil, TPO), and a gaseous product containing $\mathrm{CO}, \mathrm{CO}_{2}, \mathrm{H}_{2}, \mathrm{SO}_{2}$ (tire pyrolytic gas, TPG). All these fractions can be used in many processes, depending on their composition [2, 3]. For example, the gas fraction could be used for providing the heat required by the pyrolysis process, or it could be reformed into a hydrogenrich gas. At the same time, the solid can be used as a precursor of activated carbons, a substitute of carbon

black, as an additive for asphalt mixtures, and more recently, as a catalyst [4]. In addition, the liquid fraction, containing aromatic and aliphatic compounds (5 to 20 carbons), has a high heating value (ca. $44 \mathrm{MJ} \mathrm{kg}^{-1}$ ); thus, it has potentialities as an alternative fuel or fuel additive [2, 3, 5-7]. Moreover, advanced ideas are under discussion for taking advantage of the TPO as a building block in fine chemistry and as an additive for autohealing processes [2].

During the pyrolysis of waste tires, cracking reactions start with the rupture of S-S bonds since these have the lowest binding energy around $272.8 \mathrm{~kJ} \mathrm{~mol}^{-1}$, followed by C-S $\left(307.9 \mathrm{~kJ} \mathrm{~mol}^{-1}\right)$ and C-C $\left(377.4 \mathrm{~kJ} \mathrm{~mol}^{-1}\right)$ bonds, respectively [8]. These reactions lead to the formation of several undesired compounds that are obtained along with the valuable products (aromatic hydrocarbons, aliphatic hydrocarbons, terpenes, etc.), which hinders the 
quality and applications of the TPO. Hence, one of the challenges for valorizing WT via pyrolysis is controlling the selectivity to specific compounds, which can be achieved by using specific catalytic materials [3].

The catalytic pyrolysis can overcome some of the drawbacks mentioned above, leading to a high-rank TPO with a low content of sulfur and polycyclic aromatics compounds $[2,3,5]$. In this sense, the use of acid catalysts (mainly zeolites) has been extensively studied to upgrade TPO. In contrast, supported nano-sized metallic particles have been explored to a limited extent. In a recent study carried out by $\mathrm{Yu}$ et al [9], the $\mathrm{Cu}, \mathrm{Zn} / \mathrm{HZSM}$ 5, and $\mathrm{Cu}, \mathrm{Zn}-\mathrm{MCM}-41$ were evaluated as catalysts for improving the TPO quality. It was demonstrated that the $\mathrm{Cu}$ and $\mathrm{Zn}$ promoted the cracking of macromolecular components, dehydrocyclization and aromatization reactions, besides assisting the removal of sulfur compounds. The acid characteristic of supports and the formation of new acidic sites at the support-metal interface were responsible for the observed activity and selectivity. However, the acid catalysts can also promote the formation of high amounts of coke, which is critical for their operation stability. The coke formation has been related to the concentration of polycyclic aromatics and polar aromatics compounds, which could condense within catalyst pores. Hence, the catalyst stability can be improved by reducing the formation of these species during the pyrolysis process as have been reported elsewhere [10-12].

More recently, Jitkarnka et al. [10, 11] reported the production of light olefins and light oil from waste tires, using Ru supported over MCM-41 and SBA-15. In both cases, catalysts' presence increased the yield of light oil with a significant concentration of monoaromatics and olefins and a minor content of poly- and polararomatics compared with non-catalytic pyrolysis. A similar result was achieved on Pt-loaded zeolites (HMOR and HBETA) [12].

Other transition metals have been demonstrated to be active for transforming complex mixtures of polymeric residues [13-15] and to produce oil with an upgraded composition [16-18]. In this regard, nickel showed to promote the activity of zeolites (HZSM-5, HMOR, HY, and HBETA) by enhancing the quality of TPO in reference to its fuel properties [17]. For example, when Ni/HZSM-5 and Ni/HMOR were used as catalysts for WT pyrolysis, a lighter TPO with a higher proportion of gasoline and kerosene and lower sulfur content was obtained. In contrast, the Ni/HBETA and Ni/HY promoted heavier fractions with a high proportion of di-, poly, and polar-aromatics compared to pristine zeolites. However, according to Namchot et al. [17], both the channel 
structure and the acidic characteristics of zeolites governed the product distribution and sulfur removal, so that zeolite properties more than the metallic site strongly influenced catalytic behavior. Therefore, the specific role of Ni sites during the WT pyrolysis is not well understood as well as its kinetic and mechanistic implications remain unsolved.

From the above-discussed, it is evident that the available information on WT catalytic pyrolysis is continuously increasing, which is also posing new emerging questions. Accordingly, herein we report a comprehensive study on using $\mathrm{SiO}_{2}$-supported Ni metallic nanoparticles as catalysts for WT pyrolysis. The catalytic effect of metal clusters was insulated from that of the support since $\mathrm{SiO}_{2}$ has been demonstrated to be catalytically inactive in this reaction.

\section{Materials and Methods}

\subsection{Waste tires characterization}

The polymeric fraction of waste tires was collected from a local company. Samples were received as granules, thus they were crushed and sieved into particle sizes between 180 and $300 \mu \mathrm{m}$. The resulting fines were then analyzed for elemental composition in a Leco CHNS 628 elemental analyzer and following the ASTM D3172 Standard. Furthermore, the proximate analysis was performed in a muffle furnace (Thermo Scientific F6020C) according to the ASTM D3172 standard. Traces of inorganic elements were quantified by inductively coupled plasma optical emission spectrometry (ICP-OES) using a PerkinElmer Optima 7000 DV ICP-OES series instrument. More details of methods and equipment can be found in [19].

\subsection{Catalyst synthesis and characterization}

The synthesis of the catalyst was carried out by incipient wet impregnation using $\mathrm{Ni}\left(\mathrm{NO}_{3}\right)_{2} \cdot 6 \mathrm{H}_{2} \mathrm{O}(\geq 99.0 \%$, Merck) as the Ni precursor and $\mathrm{SiO}_{2}$ as support. The $\mathrm{SiO}_{2}$ was provided by Merck (CAS Numbers 7631-86-9), and it was crushed and sieved to particle sizes between 125 and $180 \mu \mathrm{m}$. The $\mathrm{SiO}_{2}$ was chosen as support because it has a large surface area $\left(228.4 \mathrm{~m}^{2} \mathrm{~g}^{-1}\right)$; besides it is chemically inert for waste tire pyrolysis, which allows the direct analysis of the catalytic activity of the supported nanoparticles [16]. The metallic load and impregnation volume $\left(0.27 \mathrm{~mL} \mathrm{~g}^{-1}\right)$ were adjusted to obtain $5 \% \mathrm{w} / \mathrm{w}$ for Ni loadings. The impregnated sample was dried at $100{ }^{\circ} \mathrm{C}$ in an oven for $24 \mathrm{~h}$, then calcined at $500{ }^{\circ} \mathrm{C}$ (heating rate $2{ }^{\circ} \mathrm{C} \mathrm{min}-1$ ) for $2 \mathrm{~h}$ in a muffle 
(Nabetherm LT3/12). Finally, the catalytic material was reduced at $500{ }^{\circ} \mathrm{C}$ (heating rate $2{ }^{\circ} \mathrm{C} \mathrm{min}{ }^{-1}$ ) for $2 \mathrm{~h}$ under a flow of $\mathrm{H}_{2}(20 \mathrm{~mL} / \mathrm{min}, 99.9999 \%$ Airliquide, Chile $)$ in a U-type quartz reactor (18 mm ID).

The textural properties of the catalysts were determined from nitrogen adsorption/desorption at $-196{ }^{\circ} \mathrm{C}$ using a Micromeritics Gemini VII 2390t instrument. Typically, $0.5 \mathrm{~g}$ of sample were degassed at $110{ }^{\circ} \mathrm{C}$ under a continuous flow of pure $\mathrm{N}_{2}$ for $24 \mathrm{~h}$ before the adsorption tests. The Brunauer-Emmett-Teller (BET) specific surface area, total pore volume, and pore size distribution were calculated from $\mathrm{N}_{2}$ isotherms.

The morphology and the particle size distribution of the metallic particles in the supported catalysts were determined by transmission electron microscopy (JEOL JEM-1200 EX II equipment). The average sizes of metal particles are cited in this document as the average diameter in number $(\bar{d})$ defined in Eq. 1:

$$
\bar{d}=\sum_{i} n_{i} d_{i} / \sum_{i} n_{i}
$$

Where, $n_{i}$ is the number of particles of $d_{i}$ diameter and $\sum_{i} n_{i}$ is the number of analyzed nanoparticles.

Bulk crystalline phases of the $\mathrm{Ni} / \mathrm{SiO}_{2}$ were analyzed by measuring the $\mathrm{X}$-ray diffraction patterns (XRD) in a Bruker D4 diffractometer provided with $\mathrm{CuK} \alpha$ radiation $(\lambda=0.15418 \mathrm{~nm})$. The signal was generated at $40 \mathrm{kV}$ and $20 \mathrm{~mA}$. The $2 \theta$ was scanned between $3^{\circ}$ and $90^{\circ}$ at a speed of $0.02^{\circ} / \mathrm{s}$. The crystalline phases were identified by a search-match procedure with the software Mercury 3.7, using the Crystallography Open Database (COD). Besides, the sizes of the metallic particles were estimated through the Scherrer's equation:

$L=\frac{K * \lambda}{\beta * \cos (\theta)}$

where $\mathrm{L}$ is the crystallite size in $\mathrm{nm}, \lambda$ is the $\mathrm{CuK} \alpha$ wavelength in $\mathrm{nm} ; \beta$ is the full width at half maximum intensity (FWHM) in radians, $\mathrm{K}$ is a constant near to unit; and $\theta$ is the Bragg's angle (rad).

\subsection{Experimental equipment and methods for catalytic activity}

\subsubsection{Thermogravimetric analysis (TGA)}

TGA measurements were carried out using a Shimadzu DT 50 Thermal Analyzer to evaluate the thermal events during tire decomposition with and without the catalyst. The thermogravimetric analyses were performed under flowing He $\left(50 \mathrm{~mL} \mathrm{~min}^{-1}\right)$ using $\sim 2 \mathrm{mg}$ of the $\mathrm{WT}$ and heating rates of $10,20,25$, and $40{ }^{\circ} \mathrm{C} \mathrm{min}{ }^{-1}$. The studied temperature varied from ambient to $600{ }^{\circ} \mathrm{C}[19]$. In all the experiments the catalyst-to-tire mass ratio was fixed 
at 8:1, to avoid the overloading of the TGA crucible, reducing in this way the mass and heat transfer limitations, and guarantying the measurements under a kinetically controlled regime [20].

\subsubsection{Thermogravimetric analysis coupled with Fourier Transform Infrared spectrometer (TGA-FTIR)}

TGA-FTIR experiments were performed in a thermogravimetric analyzer (TA Instruments thermobalance model Q50) coupled to a FTIR (Thermo Scientific infrared spectrometer model Nicolet is10, DTGS detector, and $\mathrm{KBr}$ windows). This experiment allows coupling the mass loss with the corresponding change in volatiles composition. In a typical experiment, the TGA and DTG profiles of WT and WT/Catalyst samples were recorded between ambient and until $600{ }^{\circ} \mathrm{C}\left(\beta=25^{\circ} \mathrm{C} \mathrm{min}-1\right)$ under flowing $\mathrm{He}\left(100 \mathrm{~mL} \mathrm{~min}^{-1}\right)$. The FTIR spectra of evolved gases were collected with a resolution of $8 \mathrm{~cm}^{-1}, 32$ scans over the Mid-IR range (4000-400 $\left.\mathrm{cm}^{-1}\right)$.

\subsubsection{Py-GC/MS analysis}

A micro-pyrolysis analyzer (CDS5200, CDS Analytical Co Ltd.) coupled with a GC/MS (Clarus 690, QS8. Perkin Elmer) was used to evaluate the effect of $\mathrm{Ni} / \mathrm{SiO}_{2}$ on product distribution. The experiments were performed in the range of higher conversion during the TGA $\left(350-450^{\circ} \mathrm{C}\right)$ and using high purity $\mathrm{He}$ as carrier gas (pure 99.996\%, BOC). The pyrolysis reactor consists of a quartz capillary tube (Length of $2 \mathrm{~cm}$ and $2 \mathrm{~mm}$

ID), place within a platinum filament, which allows a heating rate of $2000{ }^{\circ} \mathrm{C} \mathrm{s}^{-1}$. For a typical experiment 1.0 $\pm 0.1 \mathrm{mg}$ of WT was used (AD 6000 Ultra MicroBalance Perkin Elmer), and for the catalyzed reactions, the catalyst-to-waste tire ratio was fixed at 8.0. The chromatographic separation was performed with an Elite 1701 column $(30 \mathrm{~m} \times 0.25 \mathrm{~mm} \times 0.25 \mu \mathrm{m})$ which was heated from 45 to $280{ }^{\circ} \mathrm{C}$ at $2.5^{\circ} \mathrm{C} \mathrm{min}^{-1}$. The compounds were identified by their mass spectra (NIST library) using a m/z range of 30-600 Da. The total ion chromatogram (TIC) area of each chromatographic peak was used to analyze the product distribution of condensable $\mathrm{C}_{5+}$ hydrocarbons (PD) as follows:

$P D=\frac{A_{S}}{\sum A_{t c}}$

where $A_{s}$ and $\Sigma A_{t c}$ are the area of a specific component and the total area of identified condensable hydrocarbons, respectively. 


\subsection{Kinetic modeling via p(y)-isoconversional methods}

The thermal degradation of the WTs has demonstrated to be ruled by a multi-reaction mechanism, thus using a single kinetic model for its description is an oversimplification. Therefore, the kinetic describing the regular and catalytic pyrolysis of waste tires is usually studied by applying iso-conversional methods [19, 21]. At the moment, there is a myriad of kinetic studies validating the applicability of iso-conversional methods to waste tires pyrolysis [22-26]. Notably, the methods of Flynn-Wall-Osawa (FWO), Coat-Redfern (CR), Friedman and Kissinger-Akahira-Sunose (KAS) have demonstrated excellent performance for studying the kinetics of WTs pyrolysis.

Accordingly, the apparent activation energies for the thermal decomposition of WT during regular and catalytic pyrolysis were determined here by the Kissinger-Akahira-Sunose (KAS) method. It has demonstrated suitability for analyzing polymers and waste tires with a linear relationship for the whole kinetic triplet [27]. The KAS method assumes that the reaction rate is the product of two functions, one depending solely on the temperature (T), and the other depending on the fraction transformed $(\alpha)$ :

$\frac{d \alpha}{d t}=f(\alpha) k(T)$

If the temperature dependence is considered as Arrhenius-type function, and considering $\beta$ as the heating rate, the Eq. 3 can be rearranged as:

$\frac{d \alpha}{d t}=\beta\left(\frac{d \alpha}{d T}\right)=A \exp \left(\frac{-E_{a}}{R T}\right) f(\alpha)$

Which after taking natural logarithms yields:

$$
\ln \left(\frac{d \alpha}{d t}\right)=\ln \left[\beta\left(\frac{d \alpha}{d T}\right)\right]=\ln [A f(\alpha)]-\frac{E_{a}}{R T}
$$

Assuming that the apparent activation energy remains constant through the duration of the reaction (i.e., from $\mathrm{t}$ $=0$ to $t_{\alpha}$ where $t \alpha$, is the time at conversion $\alpha$ ) and integrating Eq. 5 concerning $\alpha$ and T:

$g(\alpha)=\int_{0}^{\alpha} \frac{d \alpha}{f(\alpha)}=\frac{A}{\beta} \int_{0}^{T_{\alpha}} \exp \left(\frac{-E_{a}}{R T}\right) d T$

where $\mathrm{T}_{\alpha}$ is equal to the temperature at conversion $\alpha$. If we define $\mathrm{x} \equiv \mathrm{Ea} / \mathrm{RT}$, Eq. (6) becomes:

$g(\alpha)=\frac{A E_{a}}{\beta R} \int_{\alpha}^{\alpha} \frac{\exp p^{-x}}{x^{2}}=\left(\frac{A E_{a}}{\beta R}\right) p(x)$ 
Here $\mathrm{p}(\mathrm{x})$ is the integral of the temperature which for Doyle's approximation $\log (p(x)) \cong \frac{\exp ^{-x}}{x^{2}} \quad$ leads $\quad$ to the well-known generalized equation representing the KAS's method:

$\ln \left(\frac{\beta}{T_{m}^{2}}\right)=\frac{-E a}{R}\left(\frac{1}{T_{m}}\right)+C$

where $\mathrm{T}_{\mathrm{m}}$ is the temperature at the maximum reaction rate. Assuming $\alpha$ has a fixed value, Ea can be determined from the straight-line slope obtained by plotting $\ln \left(\beta / \mathrm{T}_{\mathrm{m}}^{2}\right)$ versus $1 / \mathrm{T}_{\mathrm{m}}$.

The adequacy of the model and the pre-exponential factor in the Arrhenius equation can be determined by applying the $z(\alpha)$ function described in Vyasovkin [28].

$z(\alpha)=f(\alpha) g(\alpha)=\left(\frac{d \alpha}{d t}\right)_{\alpha} T_{\alpha}^{2}\left[\frac{\pi(x)}{\beta T_{\alpha}}\right]$

The term $\left[\frac{\pi(x)}{\beta T_{\alpha}}\right]$ in Eq. 9, can be neglected as it does not affect the shape of the $z(\alpha)$ plot; thus, an identical $z(\alpha)$ plot can be derived for different $\beta$. Therefore, the experimental $z(\alpha)$ can be elaborated by multiplying the $\left.\left(\frac{d \alpha}{d t}\right)\right|_{\alpha}$ by the corresponding $T_{\alpha}^{2}$. The resulting $z(\alpha)$ values are plotted against $\alpha$ and matched with the theoretical $z(\alpha)$ master plots. The theoretical $z(\alpha)$ is obtained from the $f(\alpha) g(\alpha)$ corresponding to different models (Table S1) [28]. Usually, these curves are represented as normalized values as:

Normalized experimental $z(\alpha)$ master plot: $\left[\left(\frac{d \alpha}{d t}\right)_{\alpha} /\left(\frac{d \alpha}{d t}\right)_{r e f}\right]\left(\frac{T_{\alpha}}{T_{r e f}}\right)^{2}$

Normalized theoretical $z(\alpha)$ master plot: $[f(\alpha) g(\alpha)] /[f(\alpha) g(\alpha)]_{\text {ref }}$

A common practice is to use $\alpha=0.5$ as a reference to derive the functions mentioned above.

Finally, the pre-exponential factor can be calculated using the definition Vyasovkin [28].

$A=\frac{-\beta E_{a}}{R T_{\max }^{2} \cdot f^{\prime}\left(\alpha_{\max }\right)} \exp \left(\frac{E_{a}}{R T_{\max }}\right)$

Where the $T_{\max }$ represents the maximum of the differential kinetic curve and $\alpha_{\max }$ is the conversion corresponding to this temperature. All graphics were created by using OriginPro 2018. 


\section{Results and Discussion}

\subsection{Waste tires characterization}

Proximate and elemental analyses displayed in Table 1, confirm the potential for using WT for pyrolysis. Volatiles fraction (VM) (58.8\%) suggests that a considerable fraction of $\mathrm{C}-\mathrm{H}$ can be recovered via pyrolysis as condensable and non-condensable gases. Furthermore, the fixed carbon (FC) (non-volatile) and ash fractions, highlight the relative importance of additives (see majoritarian elements: $\mathrm{Al}, \mathrm{Fe}$, and $\mathrm{Ca}$ ) on the applications of the solid products (i.e., recovered carbon black).

Table 1. Composition of waste tire feedstock

\begin{tabular}{ccccc|cccccc|ccc}
\hline \multicolumn{1}{c}{ Elemental composition } & \multicolumn{1}{c}{ Proximate analysis } \\
\multicolumn{1}{c}{$(\mathrm{wt} \%)$} \\
\hline $\mathrm{C}$ & $\mathrm{H}$ & $\mathrm{O} *$ & $\mathrm{~N}$ & $\mathrm{~S}$ & $\mathrm{Al}$ & $\mathrm{Ca}$ & $\mathrm{Fe}$ & $\mathrm{K}$ & $\mathrm{Na}$ & $\mathrm{MC}$ & $\mathrm{VM}$ & $\mathrm{FC}$ & Ash \\
79.5 & 7.33 & 2.77 & 0.47 & 1.48 & 1352 & 1152 & 1117 & 509 & 508 & 1.1 & 58.8 & 30.2 & 9.9 \\
\hline
\end{tabular}

*Oxygen is calculated by the difference from $\mathrm{C}, \mathrm{H}, \mathrm{N}, \mathrm{S}$, and Ash

\subsection{Catalyst characterization}

The Ni loading on the support via impregnation and followed by treatment in pure $\mathrm{H}_{2}$ did not significantly affect the support's textural properties, as evidenced by the slight variations of $\mathrm{S}_{\mathrm{BET}}$, VP, and $\mathrm{d}_{\mathrm{P}}$ in Table 2 . This observation allows inferring that after impregnation, the resulting clusters partially plugged the support pores, leading to a slight reduction in the available surface (measured as BET). According to the IUPAC classification, it is possible to identify that the average pore size of the $\mathrm{Ni} / \mathrm{SiO}_{2}$ catalyst corresponds to the range of mesoporous materials [29]. The mesoporous size of catalyst is desirable for pyrolysis applications due to the medium-sized molecules of volatiles, which should get to the surface to be converted into upgraded products (e.g., alkenes, BTX, etc.) [30]. The combination of the pore sizes (meso) with the large surface area obtained for the $\mathrm{Ni} / \mathrm{SiO}_{2}$ minimized the transport limitations during the catalytic process.

Figure 1 (a) presents a TEM micrograph for the catalyst $\mathrm{Ni} / \mathrm{SiO}_{2}$, while Fig. 1 (b) shows the particle size distributions (PSD) obtained from 200 individual particles measured in 10 TEM images. The TEM micrograph and the PSD histogram confirms that the synthesis of the $\mathrm{Ni} / \mathrm{SiO}_{2}$ allows obtaining homogeneously dispersed 
metal particles with a normal distribution centered at $11 \pm 3 \mathrm{~nm}$. Homogeneous metal dispersion has been recognized as relevant for pyrolysis [31]; hence, these values are used for normalizing the catalytic activity results during the reaction experiments.

(a)

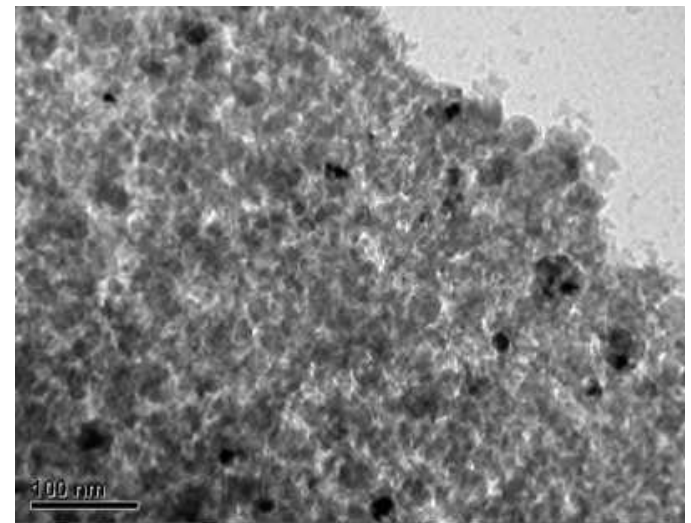

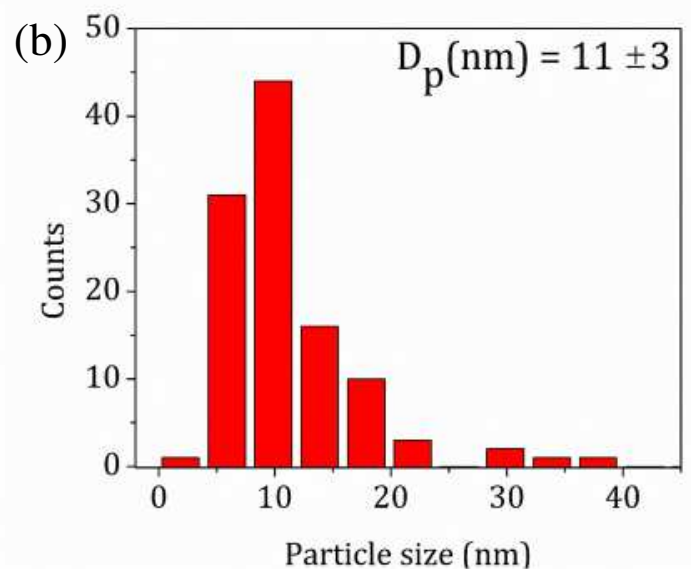

Fig. 1 a) TEM image and b) Particle size distribution, average particle size (Dp), and standard deviation for $\mathrm{Ni} / \mathrm{SiO}_{2}$ catalyst. The bar in the images represents $100 \mathrm{~nm}$.

The XRD pattern of the $\mathrm{Ni} / \mathrm{SiO}_{2}$ catalyst is shown in Fig. 2 A broad peak is observed around $2 \theta=22^{\circ}$, assigned to the [002] plane reflection of amorphous $\mathrm{SiO}_{2}[32]$.

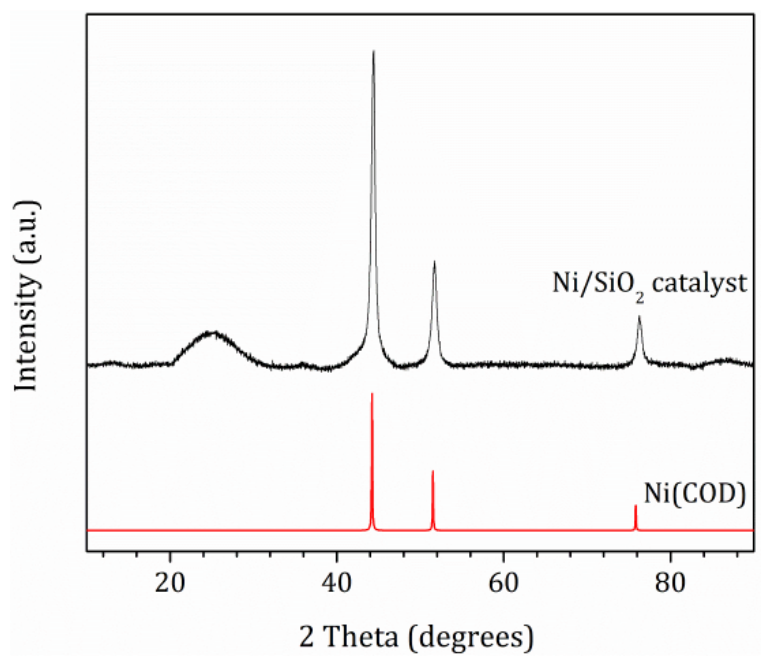

Fig. 2 XRD results of fresh Ni catalyst sample. Standards from the COD database [33] : Ni (2100637). (http://www.crystallography.net/cod/). 
In addition, an intense peak centered on $2 \theta=44.3$ and two minor peaks of 51.7 and $76.3^{\circ}$ were identified, which were associated respectively to the [111], [200] and [220] diffraction of the Ni. The absence of oxidized Ni phases after exposure of the sample to air for XRD analysis is remarkable, demonstrating the stability of the Ni metal phase on the surface.

Table 2 summarizes the textural properties of the catalyst along with some structural parameters. In $\mathrm{Ni} / \mathrm{SiO} 2$ catalyst the average particle size obtained by TEM and XRD shows a clear agreement. This similarity between the different estimation methods confirmed the accuracy of the prediction, and it indirectly validates the well homogeneous dispersion of the metallic clusters.

Table 2. Textural properties of $\mathrm{Ni} / \mathrm{SiO}_{2}$ catalyst

\begin{tabular}{|c|c|c|c|c|c|}
\hline Catalysts & $\begin{array}{l}\text { Metal Cont. } \\
\text { (\%wt. })\end{array}$ & $\begin{array}{c}\text { SBET } \\
\left(\mathrm{m}^{2} \mathrm{~g}^{-1}\right)\end{array}$ & $\begin{array}{c}\text { Vore } \\
\left(\mathrm{cm}^{3} \mathbf{g}^{-1}\right)\end{array}$ & $\begin{array}{c}\text { dp } \\
(\mathrm{nm})^{\mathrm{a}}\end{array}$ & $(\mathbf{n m})^{\mathbf{b}}$ \\
\hline $\mathrm{SiO}_{2}$ & N/A & 228.4 & 0.27 & & \\
\hline $\mathrm{Ni} / \mathrm{SiO}_{2}$ & 5 & 204.5 & 0.24 & $11 \pm 3$ & 11.25 \\
\hline \multicolumn{6}{|c|}{$\begin{array}{l}\text { aAverage particle size obtained from TEM images (Eq. } 2) ;{ }^{b} \text { Average particle size calculated } \\
\text { from XRD (Scherrer's equation). }\end{array}$} \\
\hline
\end{tabular}

\subsection{TGA-FTIR analyses}

\subsubsection{Thermogravimetric analysis}

Figure 3 (a) shows the TGA, the first (DTG), and the second derivatives (2DTG) of the weight loss for WT regular pyrolysis (non-catalytic) at a heating rate of $25^{\circ} \mathrm{C} \min ^{-1}$. For seeking clarity, the recorded TGA curve was divided into three major decomposition stages (Stage I, II, and III), which were associated with the conversion of the individual WT polymeric constituents (NR, SBR, and BR) [24, 34-36].

During the non-catalytic experiment, the DTG exhibits a maximum decomposition peak at $381{ }^{\circ} \mathrm{C}$ and a smooth shoulder centered at $\sim 405{ }^{\circ} \mathrm{C}$, respectively. This curve was then resolved through a second derivative of the TGA, confirming the overlapping of two conversion stages between 380 and $500^{\circ} \mathrm{C}$. Considering these results, stage II was subdivided into stage IIA and stage IIB, respectively.

The stage I (below $290{ }^{\circ} \mathrm{C}$ ) corresponded to a mass loss of $4.21 \%$ under uncatalyzed conditions. This decomposition stage is often attributed to the volatilization of light hydrocarbons, plasticizers, and other low boiling-point components. Stage IIA (between 381 and $410^{\circ} \mathrm{C}$ ) is ascribed to the degradation of NR; while 
stage IIB, occurring between 410 and $500{ }^{\circ} \mathrm{C}$, is characteristic of the SBR decomposition. Beyond $470{ }^{\circ} \mathrm{C}$, mass loss was attributed to BR, representing less than $13 \%$ of weight in the tires.

(a)

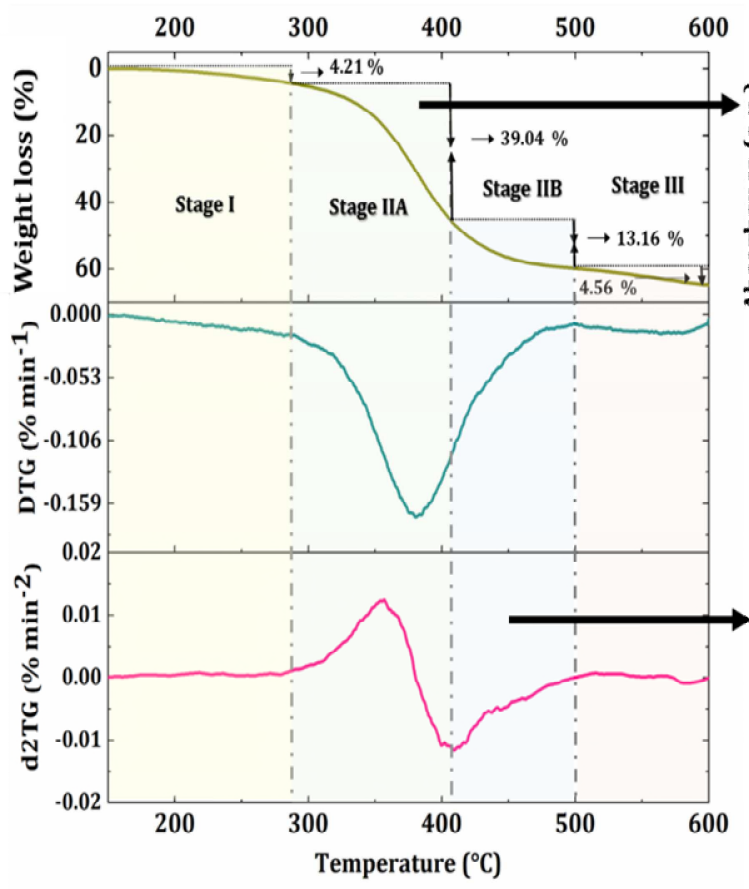

(b)
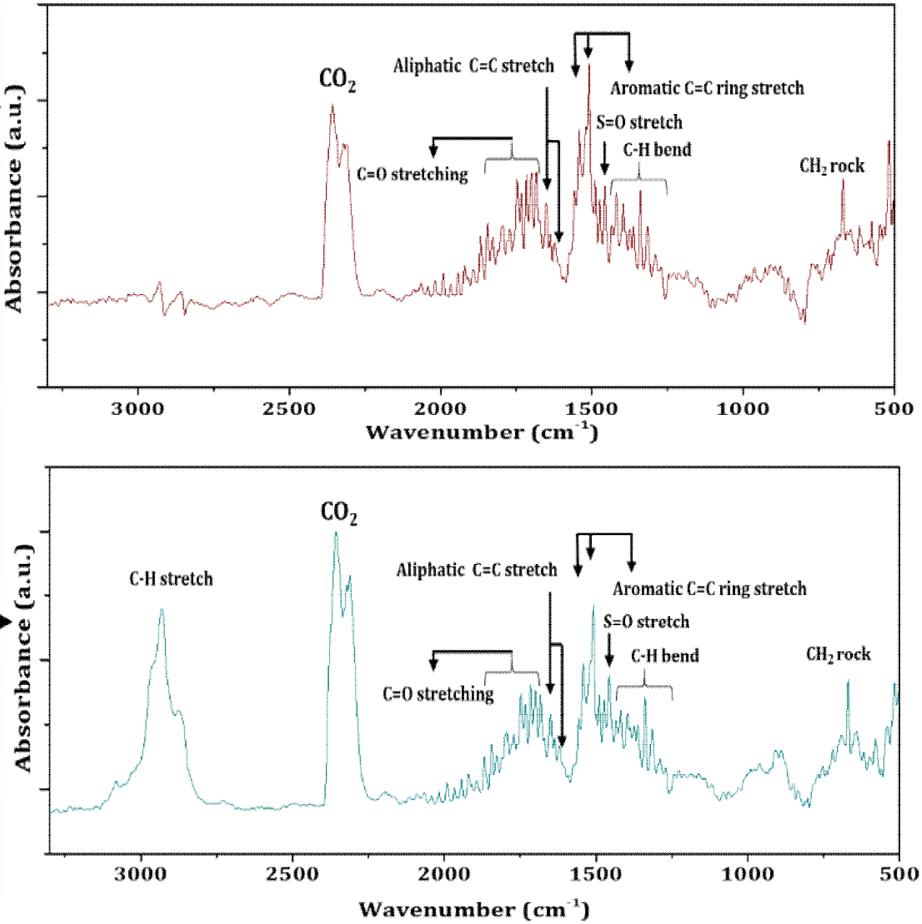

Fig. 3 (a) Thermogravimetric analyses (TGA) and its first and second derivate for non-catalytic waste tire decomposition and (b) FTIR spectra of evolved gas. (See Table S3 for signal assignment information).

The general profile of TGA, DTG, and 2DTG of the catalyzed pyrolysis of WT (Fig. 4) was similar to that of the uncatalyzed process. However, a slight shift in the characteristic temperatures for the Stages I, IIA, and IIB, and some differences in their corresponding weight losses were found when $\mathrm{Ni} / \mathrm{SiO}_{2}$ was present. This result suggests that the catalyst could be affecting depolymerization and subsequent reactions, which will be inspected more in-depth in the upcoming sections.

\subsubsection{Functional groups of evolved pyrolytic gases of TGA detected by FTIR}

By FTIR was assessed the gas evolved during the thermal decomposition of WT. Fig. 3(b) and Fig. 4(b) shows a zoom of the IR spectra for the uncatalyzed and catalyzed pyrolysis of WT in the range corresponding to Stages IIA and IIB. These regions were selected as they enclosed the highest mass loss; thus, they define the pyro-oil composition derived from WT. A complete screening of the FTIR is provided in the Supplementary Material (Fig. S1). 
(a)

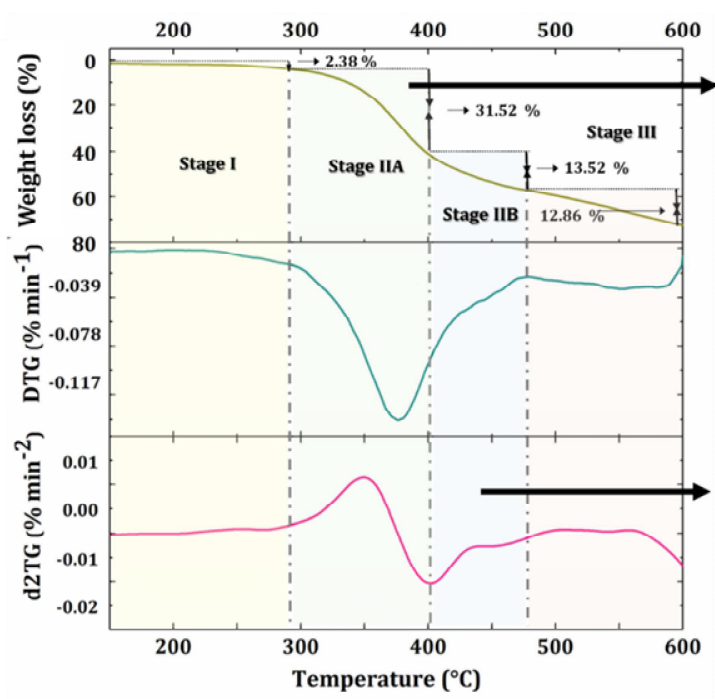

(b)
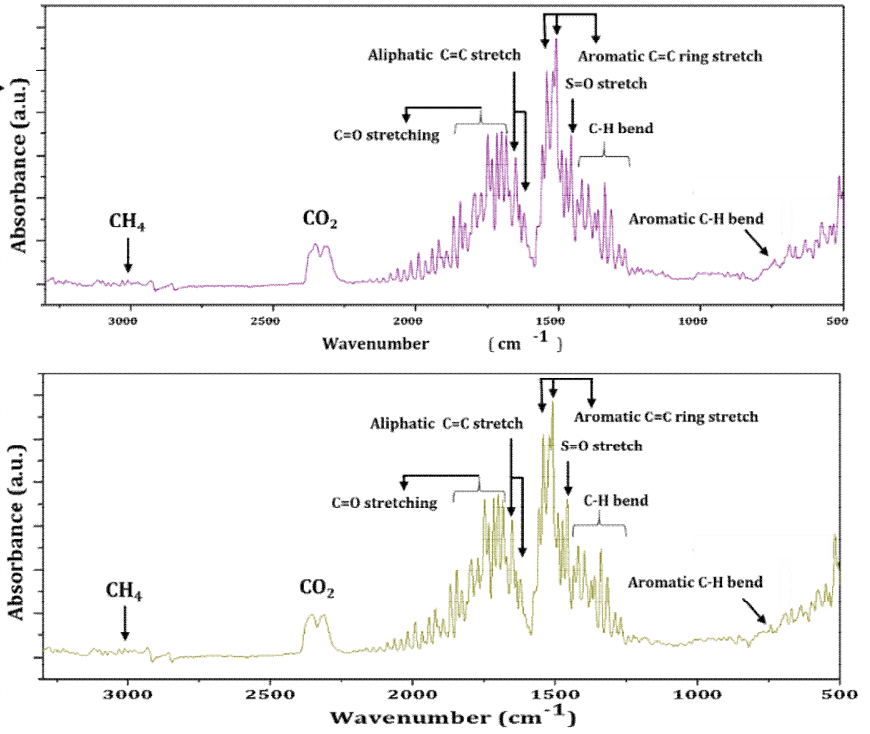

Fig. 4 (a) Thermogravimetric analyses (TGA) and its first and second derivate for catalytic waste tire decomposition and (b) FTIR spectra of evolved gas in the presence of $\mathrm{Ni} / \mathrm{SiO}_{2}$ catalyst.

As shown, the IR spectra allowed to identify the presence of aliphatic hydrocarbons such as alkanes and/or alkenes and aromatics compounds in pyrolytic gases for both experiments [37]. Particularly, the aromatic compounds associated with the bands observed between 1500 and $1600 \mathrm{~cm}^{-1}$, usually ascribed to the $\mathrm{C}=\mathrm{C}$ stretching (which often occur in pairs) were present in the catalyzed reaction. The intensity of the absorbance peaks for this region allows supposing that, in the presence of $\mathrm{Ni} / \mathrm{SiO}_{2}$, the formation of aromatics is enhanced during WT pyrolysis. This hypothesis was further confirmed by peaks appearing between 740 and $690 \mathrm{~cm}^{-1}$ only on catalyzed reaction, typically ascribed to out-of-plane bending vibrations in aromatics.

Similarly, the stretching vibrations of $\mathrm{C}=\mathrm{C}$ bonds in alkenes and conjugated dienes were detected at 1600-1670 $\mathrm{cm}^{-1}$ in both, catalyzed and uncatalyzed experiments. Meanwhile, the bands observed between 1330 and 1500 $\mathrm{cm}^{-1}$ were assigned to $\mathrm{C}-\mathrm{H}$ bending vibrations from methyl and methylene groups (See C-H ids in Fig. 3(b) and Fig. 4(b)). On the other hand, the bend vibration around $690 \mathrm{~cm}^{-1}$ observed for the uncatalyzed reaction can be due to methylene rocking vibrations $\left(\rho \mathrm{CH}_{2}\right)$. In fact, this vibration can be associated with open-chain hydrocarbons containing four or more $\mathrm{CH}_{2}$ groups, which rock in phase, pointing out to higher content of these species for the non-catalytic reaction. Moreover, the strongest absorption in $\mathrm{C}-\mathrm{H}$ stretching zone occurring in the $3000-2840 \mathrm{~cm}^{-1}$ region for the uncatalyzed experiment would confirm the presence of these species. 
The $\mathrm{C}=\mathrm{O}$ stretching vibrations between 1650 and $1750 \mathrm{~cm}^{-1}$ indicate carbonyl groups, which could be expected in reaction products derived from the additives of raw tire [38-40]. While the peaks at 2320 and $2360 \mathrm{~cm}^{-1}$ characteristic of $\mathrm{CO}_{2}$ are proposing as derived from co-pyrolysis of additives and inorganic substances [41]. The band detected at $1460 \mathrm{~cm}^{-1}$ was ascribed to sulfur-containing species [39, 42]. Finally, the formation of $\mathrm{CH}_{4}$ via cracking of the aliphatic hydrocarbons and/or aromatic and cycloalkenes ring substituents is confirmed by band at $3014 \mathrm{~cm}^{-1}$ that appeared in the catalyzed pyrolysis [42].

The effect of using $\mathrm{Ni} / \mathrm{SiO}_{2}$ on the formation of alkenes and aromatics at different temperatures could be semiquantitatively evaluated through absorbance since, according to Bouguer-Lambert-Beers law, the absorbance is linearly dependent on the corresponding gas concentration at a specific wavelength [42-44]. Therefore, the TGA-FTIR data was used as a semi-quantitative measure for the abundance of these functionalities in the evolved gas (Fig. S2). With this aim, the $\mathrm{C}=\mathrm{C}$ stretching bands were chosen as markers for identifying alkenes and aromatics as they appear at different wavelengths for these species. Figure S2 shows that with catalyst, the absorbance of both alkenes and aromatics increased until $400{ }^{\circ} \mathrm{C}$. A plateau is then reached, mainly for aromatic compounds, while both functionalities have a sustained increase for the uncatalyzed reaction. Besides, absorbance values were always much higher in catalyst presence. This observation could be related to an increased reaction rate for catalyzed reaction with $\mathrm{Ni} / \mathrm{SiO}_{2}$, leading to a quasi-steady state condition at lower temperatures than the uncatalyzed process.

\subsection{Evaluation of pyrolytic products via Py-GC/MS analysis}

The Py-GC/MS technique allows evaluating the catalyst effect during fast pyrolysis of the waste tire. A detailed list of the main identified compounds is provided in the supplementary material (Table S2). The product distribution was determined concerning the total area of identified compounds (Eq. 3) and the conversion of tire samples (Fig. 5a). Seeking for clarifying, the compounds were classified into three major groups: monocyclic aromatics, alkenes, and additives. Alkenes group includes cycloalkenes, isoprene, aliphatic terpenes, and limonene. The trend in the product distribution obtained from the Py-GC/MS agrees with the semi-quantitative results of the TGA-FTIR study. Since the $\mathrm{SiO}_{2}$ support showed the same behavior on the product distribution that uncatalyzed reaction (Fig. S3), the catalytic activity found in the present study was attributed to the Ni metallic sites. 
As shown in Fig. 5a, the main differences between catalyzed and non-catalyzed reactions were detected below $450{ }^{\circ} \mathrm{C}$. At lower temperature evaluated $\left(350{ }^{\circ} \mathrm{C}\right), \mathrm{Ni} / \mathrm{SiO}_{2}$ catalyst seems to favor the formation of alkenes, mainly cycloalkenes (Fig. 5a and 5b). Meanwhile, an increase in temperature at $400{ }^{\circ} \mathrm{C}$ resulted in a rise in monoaromatics content (Fig. 5a), mainly BTX, on the same reaction. These latter represent $28.1 \%$ of monoaromatics (Fig. 5c), while without catalyst only reach 9.7\%. The increase in monoaromatics could occur at the expense of DL-limonene and cycloalkenes, as shown in Fig. 5b (red squares and triangles). It agrees with reaction pathways suggested by $[9,16,45]$. In this sense, Ding et al.[45], also reported that the main products of pyrolysis of D,L-limonene, and BR were cycloalkenes in both cases, and these participated in the subsequent reactions leading to aromatics. The promotion of aromatization from cycloalkenes by using metal catalysts was also presented by $\mathrm{Yu}$ et al.[9] on $\mathrm{Cu} / \mathrm{MCM}-41$ catalysts. However, in this case, observed activity was ascribed to the medium-strong Lewis acid sites rather than metal participation.

It is worth highlighting that a higher formation of open chain alkenes was found on uncatalyzed reaction than on the catalyzed one at $400{ }^{\circ} \mathrm{C}$, confirming that when Ni-catalyst was present, promotion of cyclization reactions was observed. At the highest temperature $\left(450^{\circ} \mathrm{C}\right)$, no significant differences were detected regardless of the presence or absence of catalyst for open-chain alkenes. However, for limonene and cycloalkenes, the catalyst leads to a reduction of $8 \%$ and $5 \%$ of the selectivity (Fig. 5b). This result correlates with the SBR and PB rubbers, which require a higher temperature for its depolymerization (Fig. 3 and 4), given rise to these species when temperature increase [46]. For uncatalyzed reaction, the temperature raising led to an increasing in alkenes formation while the composition of aromatic compounds did not change significantly for any studied temperatures. Previous results could indicate that secondary reactions such as $\mathrm{C}-\mathrm{C}$ bond scission, cyclization, and aromatization are being promoted by Ni catalyst [47]. 

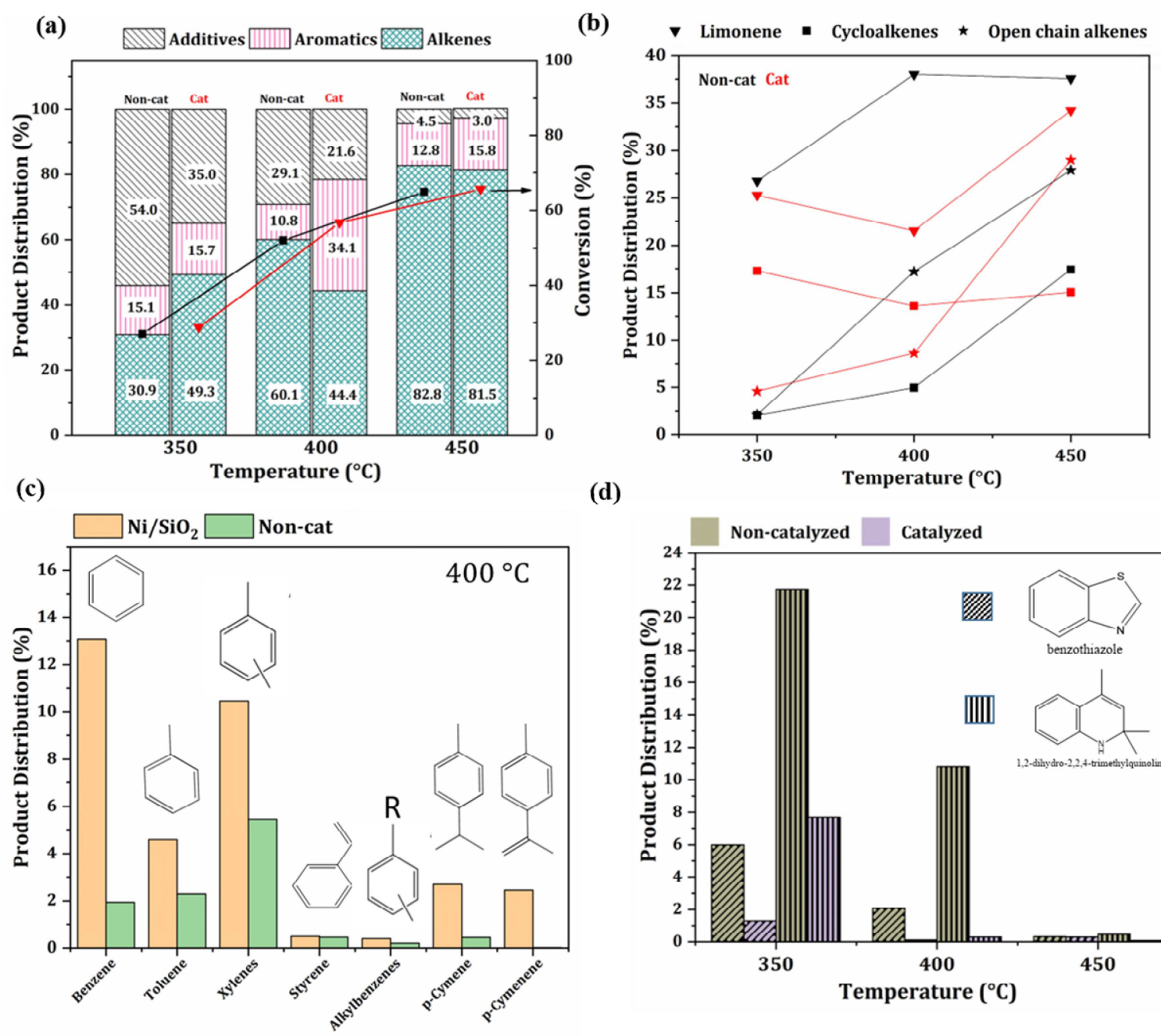

(d)

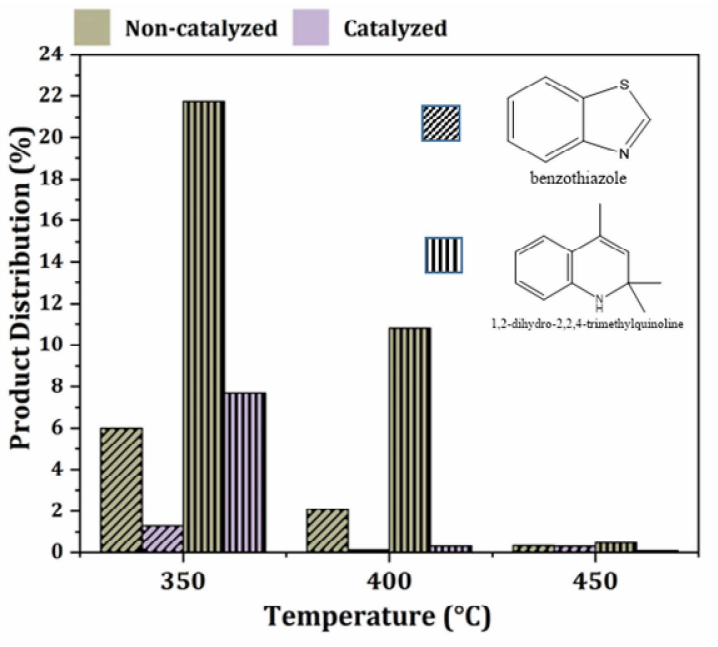

Fig. 5 Effect of temperature and use of Ni catalyst on (a) product distribution (b) limonene and alkenes content, (c) monoaromatics content, and (d) N-and S-compounds content, during waste tire pyrolysis.

On the other hand, heteroatoms-containing compounds as nitrogen, sulfur, and oxygen (named additives in Fig. 5a) were also detected in the pyrolysis products. The main compound detected N-containing was 1,2-dihydro2,2,4-trimethylquinoline, and S-containing was benzothiazole coming from antioxidants and vulcanizing accelerator, respectively, in agreement with previous reports [3, 48-50]. As shown in Fig. 5d, Ni catalyst and temperature contribute to reducing the content of these additives, improving the quality of the pyrolytic liquid $[48,50]$.

According to the results, the $\mathrm{Ni} / \mathrm{SiO}_{2}$ catalyst could be an interesting alternative to obtain a pyrolytic oil enriched with cycloalkenes and/or monocyclic aromatic compounds (mainly BTX) at low temperatures. Besides, Ni- 
catalyst supported on $\mathrm{SiO}_{2}$ did not promote reactions conducting to the formation of polyaromatic compounds due to its low acidity, compared with bifunctional Ni-catalysts supported on zeolites [17]. This characteristic could enhance the catalyst stability as the coke deposits have been related to the formation of polycyclic aromatics and polar aromatics compounds [10-12]. Figure S4 shows the catalyst and support acidity as determined by TPD-NH .

\subsection{Implications of $\mathrm{Ni}$-catalyst presence on reaction pathways}

The D,L-limonene, has been reported as a major product during waste tire pyrolysis $[19,51-54]$. This study detected a percentage oscillating between 20 and $40 \%$ of the total chromatogram area, with or without the catalyst. The D,L-limonene is mainly generated from the degradation of natural rubber by $\beta$-bond scission with respect to the double bonds of the main polymer chain (Fig. 6).

The allylic radical, thus formed, subsequently undergoes an intramolecular cyclization and $\beta$-bond scission to form D,L-limonene. In addition, this radical can also unzip toward the isoprene monomer. The isomerization and dehydrogenation reactions of limonene lead to p-cymene formation (Fig. 5c) detected mainly on Ni catalyst since, as it is known, both reactions can be favored over this catalyst [55, 56]. Finally, dealkylation reactions of p-cymene can lead to monocyclic aromatics formation, as was observed with catalyst presence.

On the other hand, alkenes and cycloalkenes can derive from the degradation of natural, styrene-butadiene and butadiene rubber, which occurs at different temperatures (NR $<$ SBR $<$ BR) according to results shown in section 3.31. From NR the DL-limonene formed undergoes $\mathrm{C}-\mathrm{C}$ bond rupture in the $\beta$ position of the ring, resulting in a diradical diene, further transformed into an alkatriene. After that, the cyclization of this alkatriene leads to cycloalkenes formation (1,5,5,6-tetramethyl-1,3-cyclohexadiene and 5-ethyl-1,5-dimethyl-1,3cyclohexadiene and isoprene), observed in higher amount in catalyzed reaction than in the uncatalyzed process (Fig. 5b).

This observation suggests that $\mathrm{Ni} / \mathrm{SiO}_{2}$ is favoring the cracking reactions of DL-limonene, which would agree with its decrease observed between 350 and $400{ }^{\circ} \mathrm{C}$ for catalyzed pyrolysis. Subsequent aromatization and dealkylation reactions of these cycloalkenes resulted in the formation of monocyclic aromatic compounds. These aromatization reactions were mainly observed on Ni catalyst since the content of aromatic compounds doubled by raising the temperature at $400{ }^{\circ} \mathrm{C}$ (Fig. 5a). Conversely, for uncatalyzed pyrolysis, aromatics content 
remained constant. The favoring of these reactions is related to the known ability of Ni catalysts to participate in the dehydrogenation reactions [56].

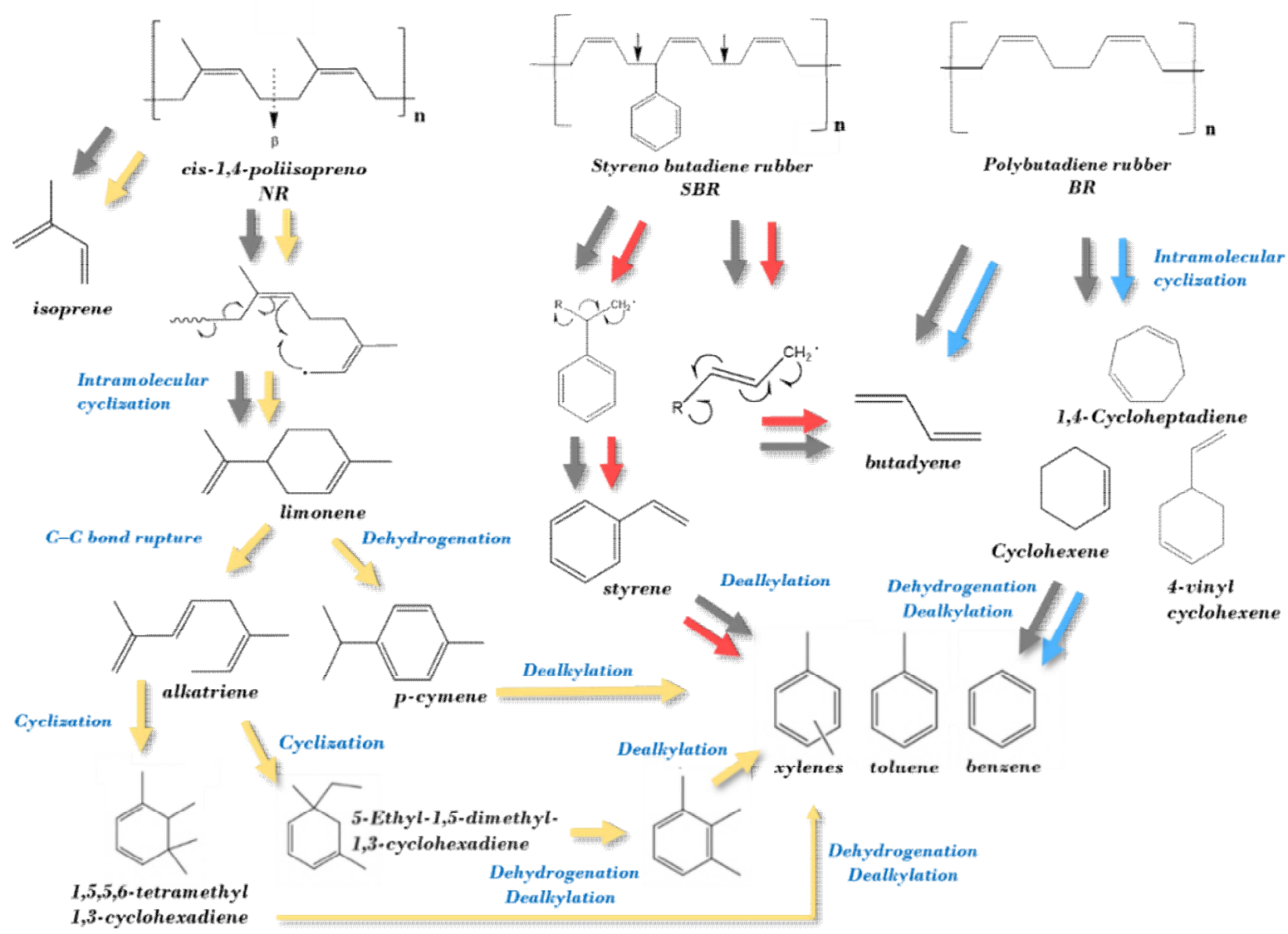

Fig. 6 Suggested reaction pathways of waste tire pyrolysis carried out with or without catalyst. $\mathrm{Ni} / \mathrm{SiO}_{2}$ catalyst: colored arrows (light yellow:NR, red:SBR, blue:BR), uncatalyzed reaction: gray arrows.

Decomposition of BR produces butadiene, 4-ethenyl-cyclohexene, 1,4-cycloheptadiene, and cyclohexene from direct depolymerization or/and then cyclization of depolymerized radicals [45]. All these compounds were detected within the pyrolytic products except butadiene. Meanwhile, from SBR decomposition are obtained butadiene and styrene. This latter was observed in reaction products (Fig. 5c). As from $400{ }^{\circ} \mathrm{C}$, the decomposition of these rubbers would be responsible for the increase in alkenes content detected (Fig. 5a). Afterward, monocyclic aromatic compounds can be generated from these rubbers by cycloalkenes dehydrogenation reactions. These results suggest that $\mathrm{Ni} / \mathrm{SiO}_{2}$ catalyst is promoting secondary reactions leading 
to the formation of cycloalkenes and monocyclic aromatics compounds at low temperatures. Therefore, it is worth noticing that the use of $\mathrm{Ni} / \mathrm{SiO}_{2}$ will lead to a pyro-oil with upgraded fuel properties, enhanced by the increment in monoaromatics and alkenes.

Figure 6 shows reaction pathways leading to identified products and those favored mainly in catalyzed reaction.

\subsection{Kinetic analysis}

\subsubsection{Isoconversional method}

The results from the derivative thermal analysis (DTG) show a remarkable effect of the heating rate $(\beta=10,20$, $25,40^{\circ} \mathrm{C} / \mathrm{min}$ ) on the position of the maximum decomposition rate for catalytic (Fig. 7a) and non-catalytic (Fig. 7b) pyrolysis. The $\mathrm{T}_{\max }$ position shifted to higher temperatures as the heating rates increased, regardless of catalyst use. Moreover, the $\mathrm{T}_{\max }$ values of catalytic experiments (over $\left.\mathrm{Ni} / \mathrm{SiO}_{2}\right)$ are lower $\left(5^{\circ} \mathrm{C}<\Delta \mathrm{T}_{\max }<10^{\circ} \mathrm{C}\right)$ than those for non-catalytic assays at a fixed $\beta$. The kinetic implications of such behavior were inspected by the Kissinger's method for which the plot $\ln \left(\beta / \mathrm{T}_{\mathrm{m}}{ }^{2}\right.$ versus $\left.1 / \mathrm{T}_{\mathrm{m}}\right)$ depicted a linear tendency with a good correlation coefficient (See inserts in Fig. $7 \mathrm{a}$ and $7 \mathrm{~b}$ ). The $\mathrm{T}_{\max }$ position in all the cases was always below $50 \%$ of conversion $(\alpha \max <50 \%)$, indicating that the reaction is in the nominal region, where integral methods are adequate.

The activation energy calculated for the $\mathrm{Ni} / \mathrm{SiO}_{2}$-catalyzed pyrolysis was $111.0 \mathrm{~kJ} \mathrm{~mol}^{-1}$; while the uncatalyzed process resulted in $168.4 \mathrm{~kJ} \mathrm{~mol}^{-1}$. This difference between the Ea values, demonstrates an important catalytic effect of the $\mathrm{Ni} / \mathrm{SiO}_{2}$, which could be explained by changes in the reaction routes taking place or due to the formation of stable complexes. The Ea values agree with previous literature for similar residues and different kinetic methods $[19,26]$. With the Ea values in hand, a proposal of a plausible reaction model can be done by using the $\mathrm{z}(\alpha)$ and $\mathrm{y}(\alpha)$ master plots approach.

\subsubsection{Proposal of a reaction model via Master Plots}

As discussed before, the pyrolysis of WTs is ruled by a complex reaction mechanism, which could vary according to the decomposition stage taking place. Therefore, the kinetic model's proposal and the estimating of the corresponding kinetic triplet are not a trivial procedure. According to Vyazovkin [28] the use of master 
plots (i.e., $\mathrm{z}(\alpha)$-plot and $\mathrm{y}(\alpha)$-plot) concept for the elucidation of reaction models describing heterogeneous reactions could bring good results for WTs pyrolysis.
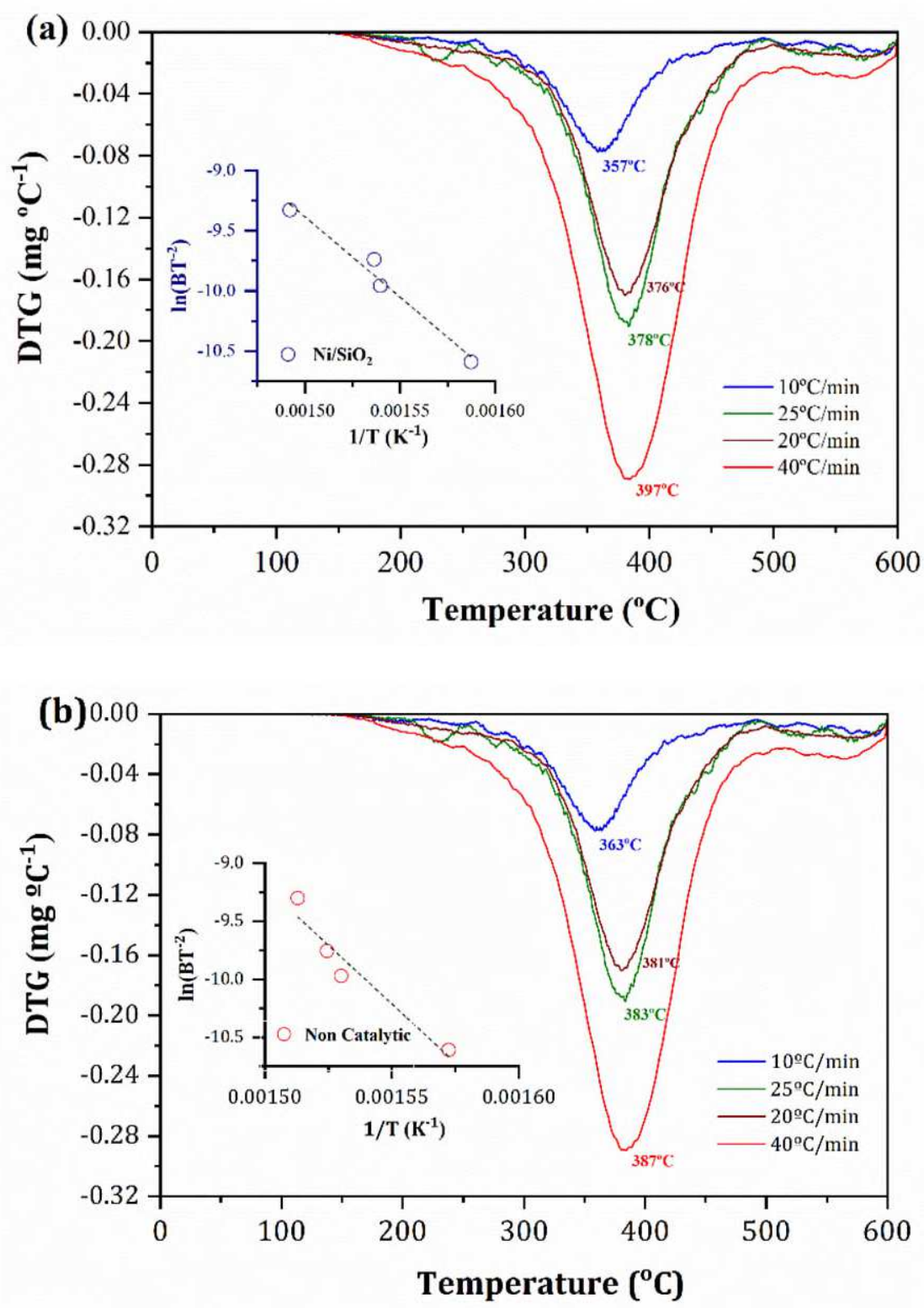

Fig. 7 DTG curves for WTs at different heating rates $\left(\beta=10,20,25,40{ }^{\circ} \mathrm{C} \mathrm{min}^{-1}\right)$ with (a) $\mathrm{Ni} / \mathrm{SiO}_{2}$ catalyst and (b) under non-catalytic conditions. The insert shows the KAS kinetic model curve.

Figure 8 shows the $(\alpha)$-plot and $\mathrm{y}(\alpha)$-plots for the non-catalytic and $\mathrm{Ni} / \mathrm{SiO}_{2}$-catalyzed WTs pyrolysis along with the kinetic models (Table S1), which better described the experimental observations. The shape of the 
experimental $\mathrm{y}(\alpha)$-plots ( $\alpha$ dependence with a maximum) for the non-catalytic and $\mathrm{Ni} / \mathrm{SiO}_{2}$-catalyzed pyrolysis allows supposing that the Avrami-Erofeev or truncated Sestak-Berggren models can fix the data. In the case of the non-catalytic pyrolysis, the $\mathrm{y}(\alpha)$-plot for the A2 model correlates to the experimental data with a $\mathrm{R}^{2}>99 \%$, in the whole conversion range, while the $z(\alpha)$-plot coincides with the same model for $\alpha<0.5$. Nevertheless, above $50 \%$ of conversion the $\mathrm{z}(\alpha)$-plot diverged from the Avrami-Erofeev model and is better described by the random scission L2 model $\left(\mathrm{R}^{2}>81 \%\right)$. This multi-model behavior is in-line with that reported by Qu et al. [21] for the WTs pyrolysis catalyzed with $\mathrm{MnO}_{2}$ and corresponds to the different reaction pathways that NR, SBR and BR undergo during pyrolysis (Fig. 6). Finally, the Avrami analysis is rather a mathematical representation of the experimental data than a way for obtaining physical insights into the pyrolysis kinetics.

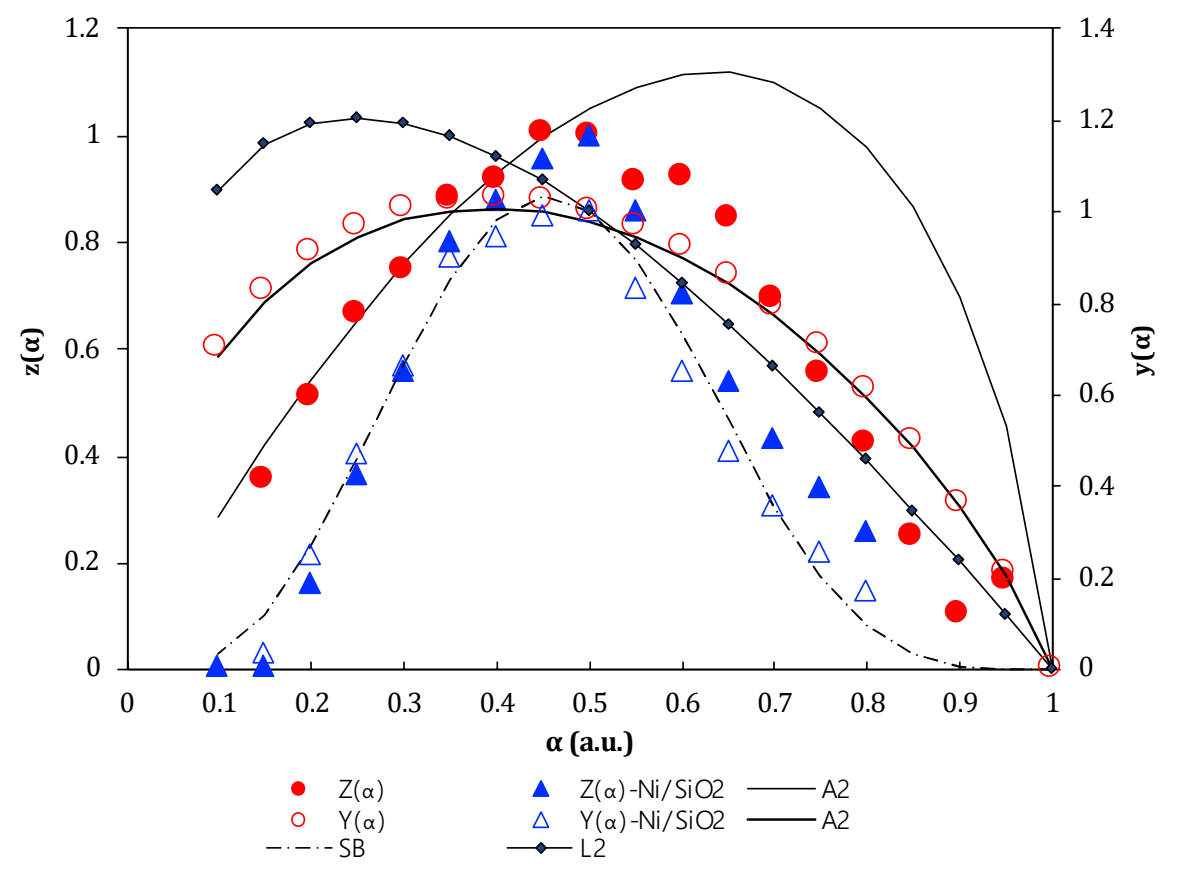

Fig. 8 Elucidation of reaction models by the $\mathrm{z}(\alpha)$-plot and $\mathrm{y}(\alpha)$-plot. Continuous lines represent the theoretical models. The empty and filled markers refer to experimental $\mathrm{z}(\alpha)$ and $\mathrm{y}(\alpha)$, respectively.

The trend in the experimental $\mathrm{y}(\alpha)$-plot for the $\mathrm{Ni} / \mathrm{SiO}_{2}$-catalyzed pyrolysis of WTs, was described by the truncated Sestak-Berggren model $(\mathrm{SB})\left(f(\alpha)=\alpha^{m}(1-\alpha)^{n} ; n=1.9, m=1.5\right)$ with a $\mathrm{R}^{2}>95 \%$. The applicability of the SB model to the catalytic pyrolysis is reasonable as the parameters $n$ and $m$ in the theoretical model were adjusted to describe the experimental $f(\alpha)$ data. This procedure is suggested by Vyazovkin [28] for treating the typical subjectivity for model selection and minimizing the errors associated with the idealized 
precepts supporting typical kinetic models. The maxima in the $y(\alpha)$-plot for the SB model can be estimated as $\alpha_{m}=n /(n+m)$ and is placed at $\alpha=0.44$. In fact, the maxima of the $y(\alpha)$-plot and $z(\alpha)$-plot coincide with this value, validating the predictions of the model. Therefore, the $T_{\max }$ value at $\alpha=0.44$ was substituted in Eq. 12 along with the corresponding kinetic model, resulting in $\mathrm{A}=3.5 \times 10^{10}\left(\mathrm{~s}^{-1}\right)$ for the $\mathrm{Ni}_{\mathrm{i}} / \mathrm{SiO}_{2}$-catalyzed pyrolysis and $\mathrm{A}=1.7 \times 10^{15}\left(\mathrm{~s}^{-1}\right)$ for regular pyrolysis conditions. These values are also in-line with that reported in Teng et al. [25] and Qu et al. [21]. The use of iso-conversional kinetic models along with master plots allowed support the multiple-step reaction mechanism.

Finally, the influence of mass and heat transfer limitations on the kinetic data was checked by applying the relation between thermal Biot and the so-called Py- numbers for reaction/conduction $\left(\mathrm{Py}^{\mathrm{I}}\right)$ and for reaction/convection $\left(\mathrm{Py}^{\mathrm{II}}\right)$ time scales [57]. The values of these parameters were evaluated between 400 and $500^{\circ} \mathrm{C}\left(\right.$ Biot $>1,10^{-3}<\mathrm{Py}^{\mathrm{I}}<10^{-1}$ and $\left.10^{-2}<\mathrm{Py}^{\mathrm{I}}<10^{-3}\right)$ and compared to the criteria defined by Pyle and Zaror [57], confirming that the process is taking place between the kinetic and the convection-limited regimes. Accordingly, the kinetic analysis for solid decomposition is not highly affected by the transport limitations; thus, it represents the reaction mechanism taking place.

\section{Conclusions}

The effect of using a $\mathrm{Ni} / \mathrm{SiO}_{2}$ as a catalyst during the pyrolysis of waste tires was assessed by analyzing the composition of vapors. Experiments in Py-GC/MS and thermogravimetric analysis allow elucidating a plausible reaction pathway and a consistent kinetic model, respectively. The main products determined were D,Llimonene, isoprene, benzene, toluene, xylenes, p-cymene, and $\mathrm{N}$ - and/or S-containing compounds. The $\mathrm{Ni} / \mathrm{SiO}_{2}$ catalyst promoted the cyclization reactions at lower temperatures (i.e., $350{ }^{\circ} \mathrm{C}$ ), leading to higher cycloalkenes content than the uncatalyzed process. While at higher temperatures $\left(400^{\circ} \mathrm{C}\right)$, the catalyst favored the formation of monocyclic aromatic compounds at expenses of D,L-limonene, and in a minor extent of cycloalkenes. Our observations indicate that zero-valent $\mathrm{Ni}$ sites promote the $\mathrm{C}-\mathrm{C}$ bond scission, cyclization, and aromatization. Additionally, the low acidity of support used in this study prevented the formation of polycondensed aromatic compounds reported in the literature for this type of reaction, which leads to the decreasing of pyrolytic oil quality. The use of iso-conversional kinetic models along with master plots allows proposing a multiple-step 
reaction mechanism, which was well described by Avrami-Erofeev, Random Scission, and truncated SestakBerggren models. Differences between the Ea values for the catalyzed $\left(111.0 \mathrm{~kJ} \mathrm{~mol}^{-1}\right)$ and the non-catalyzed $\left(168.4 \mathrm{~kJ} \mathrm{~mol}^{-1}\right)$ pyrolysis could be ascribed to the catalytic effect.

\section{Acknowledgements}

The authors thank Francisco Medina (UBB) and Magdalena Palacio (CINDECA) for their collaboration in the Py-GC/MS and TGA-FTIR measurements, respectively, as well as to the projects FONDECYT Postdoctoral 3190610, FONDEQUIP EQMI170077, FONDECYT1190063 and CONICYT PIA/Apoyo CCTE 170007 for the financial support.

\section{Declarations}

Funding: Research was financial support by projects FONDECYT Postdoctoral 3190610, FONDEQUIP EQMI170077, FONDECYT1190063 and CONICYT PIA/Apoyo CCTE 170007.

Conflicts of interest/Competing interests> The authors declare that they have no known competing financial interests or personal relationships that could have appeared to influence the work reported in this paper.

Availability of data and material: The datasets generated during and/or analyzed during the current study are included in this published article and its supplementary information files. Those data not included are available from the corresponding author on reasonable request.

Code availability: Not applicable

Authors' contributions: Conceptualization: Luis E. Arteaga-Perez, Paula Osorio-Vargas; Methodology: Paula Osorio Vargas, Ileana D. Lick, Luis E. Arteaga-Perez, Raydel Manrique; Formal analysis and investigation: Paula Osorio Vargas, Ileana D. Lick, Tamara Menares, Felipe Sobrevia and Daniela Correa-Muriel; Writing original draft preparation: Luis E. Arteaga-Perez, Paula Osorio-Vargas, Raydel Manrique; Writing - review and editing: Luis E. Arteaga-Perez, Paula Osorio-Vargas, Raydel Manrique, Ileana D. Lick, Monica Casella; Funding acquisition: Luis E. Arteaga-Perez, Paula Osorio-Vargas, Ileana D. Lick, Monica Casella; Resources: 
Luis E. Arteaga-Perez, Paula Osorio-Vargas, Ileana D. Lick, Monica Casella; Supervision: Luis E. ArteagaPerez, Paula Osorio-Vargas

Ethics approval: Not applicable

Consent to participate: All authors have read and approved the manuscript and they agree the order of authors listed in the text.

Consent for publication: All authors agree to publish the manuscript.

\section{References}

1. WBCSD: Global ELT Management - A global state of knowledge on collection rates, recovery routes, and management methods. (2018)

2. Arabiourrutia, M., Lopez, G., Artetxe, M., Alvarez, J., Bilbao, J., Olazar, M.: Waste tyre valorization by catalytic pyrolysis - A review. Renew. Sustain. Energy Rev. 129, 109932 (2020).

https://doi.org/10.1016/j.rser.2020.109932

3. Hita, I., Arabiourrutia, M., Olazar, M., Bilbao, J., Arandes, J.M., Castaño Sánchez, P.: Opportunities and barriers for producing high quality fuels from the pyrolysis of scrap tires. Renew. Sustain. Energy Rev. 56, 745-759 (2016). https://doi.org/10.1016/j.rser.2015.11.081

4. Wang, F., Gao, N., Quan, C., López, G.: Investigation of hot char catalytic role in the pyrolysis of waste tires in a two-step process. J. Anal. Appl. Pyrolysis. 146, 1-10 (2020).

https://doi.org/10.1016/j.jaap.2019.104770

5. Kumaravel, S.T., Murugesan, A., Kumaravel, A.: Tyre pyrolysis oil as an alternative fuel for diesel engines - A review. Renew. Sustain. Energy Rev. 60, 1678-1685 (2016).

https://doi.org/10.1016/j.rser.2016.03.035

6. Umeki, E.R., de Oliveira, C.F., Torres, R.B., Santos, R.G. dos: Physico-chemistry properties of fuel blends composed of diesel and tire pyrolysis oil. Fuel. 185, 236-242 (2016). 
https://doi.org/10.1016/j.fuel.2016.07.092

7. Rodríguez, E., Palos, R., Gutiérrez, A., Arandes, J.M., Bilbao, J.: Production of Non-Conventional Fuels by Catalytic Cracking of Scrap Tires Pyrolysis Oil. Ind. Eng. Chem. Res. 58, 5158-5167 (2019). https://doi.org/10.1021/acs.iecr.9b00632

8. Yu-Ran Luo: Handbook of Bond Dissociation Energies in Organic Compounds. (2004)

9. Yu, J., Liu, S., Cardoso, A., Han, Y., Bikane, K., Sun, L.: Catalytic pyrolysis of rubbers and vulcanized rubbers using modified zeolites and mesoporous catalysts with $\mathrm{Zn}$ and $\mathrm{Cu}$. Energy. 188, (2019). https://doi.org/10.1016/j.energy.2019.116117

10. Dũng, N.A., Klaewkla, R., Wongkasemjit, S., Jitkarnka, S.: Light olefins and light oil production from catalytic pyrolysis of waste tire. J. Anal. Appl. Pyrolysis. 86, 281-286 (2009). https://doi.org/10.1016/j.jaap.2009.07.006

11. Dũng, N.A., Tanglumlert, W., Wongkasemjit, S., Jitkarnka, S.: Roles of ruthenium on catalytic pyrolysis of waste tire and the changes of its activity upon the rate of calcination. J. Anal. Appl. Pyrolysis. 87, 256-262 (2010). https://doi.org/10.1016/j.jaap.2010.01.004

12. Dũng, N.A., Wongkasemjit, S., Jitkarnka, S.: Effects of pyrolysis temperature and Pt-loaded catalysts on polar-aromatic content in tire-derived oil. Appl. Catal. B Environ. 91, 300-307 (2009). https://doi.org/10.1016/j.apcatb.2009.05.038

13. Singh, M.V., Deformation of virgin HD-PE, PP and waste PP Plastics into green fuel via a Pyrolysiscatalytic using a $\mathrm{NiCO}_{3}$ catalyst. Indian Chem. Eng. 61, 254-268 (2019). https://doi.org/10.1080/00194506.2018.1548949

14. Singh, M.V., Kumar, S., Sarker, M.: Waste HD-PE plastic, deformation into liquid hydrocarbon fuel using pyrolysis-catalytic cracking with a $\mathrm{CuCO}_{3}$ catalyst. Sustain. Energy Fuels. 2, 1057-1068 (2018). https://doi.org/10.1039/c8se00040a

15. Singh, M.V., Waste and virgin high-density poly(ethylene) into renewable hydrocarbons fuel by pyrolysis-catalytic cracking with a $\mathrm{CoCO}_{3}$ catalyst. Elsevier B.V. (2018)

16. Osorio-Vargas, P., Menares, T., Lick, D., Casella, M.L., Romero, R., Jiménez, R., Arteaga-Pérez, 
L.E.: Tuning the product distribution during the catalytic pyrolysis of waste tires: The effect of the nature of metals and the reaction temperature. Catal. Today. (2020).

https://doi.org/10.1016/j.cattod.2020.10.035

17. Namchot, W., Jitkarnka, S.: Impacts of nickel supported on different zeolites on waste tire-derived oil and formation of some petrochemicals. J. Anal. Appl. Pyrolysis. 118, 86-97 (2016).

https://doi.org/10.1016/j.jaap.2016.01.001

18. Muenpol, S., Jitkarnka, S.: Effects of Fe supported on zeolites on structures of hydrocarbon compounds and petrochemicals in waste tire-derived pyrolysis oils. J. Anal. Appl. Pyrolysis. 117, 147-156 (2016). https://doi.org/10.1016/j.jaap.2015.12.003

19. Menares, T., Herrera, J., Romero, R., Osorio, P., Arteaga-Pérez, L.E.: Waste tires pyrolysis kinetics and reaction mechanisms explained by TGA and Py-GC/MS under kinetically-controlled regime. Waste Manag. 102, 21-29 (2020). https://doi.org/10.1016/j.wasman.2019.10.027

20. Menares, T., Catalytic pyrolysis of waste tires: Elucidating the reaction kinetics, mechanisms and catalysts effects on product distribution, (2019)

21. Qu, B., Li, A., Qu, Y., Wang, T., Zhang, Y., Wang, X., Gao, Y., Fu, W., Ji, G.: Kinetic analysis of waste tire pyrolysis with metal oxide and zeolitic catalysts. J. Anal. Appl. Pyrolysis. 152, (2020). https://doi.org/10.1016/j.jaap.2020.104949

22. Khiari, B., Kordoghli, S., Mihoubi, D., Zagrouba, F., Tazerout, M.: Modeling kinetics and transport phenomena during multi-stage tire wastes pyrolysis using Comsol®. Waste Manag. 78, 337-345 (2018). https://doi.org/10.1016/j.wasman.2018.06.002

23. Arabiourrutia, M., Lopez, G., Aguado, R., Bilbao, J., Olazar, M.: Coupling gas flow pattern and kinetics for tyre pyrolysis modelling. Chem. Eng. Sci. 201, 362-372 (2019)

24. Leung, D.Y.C., Wang, C.L.: Kinetic modeling of scrap tire pyrolysis. Energy and Fuels. 13, 421-427 (1999). https://doi.org/10.1021/ef9801241

25. Teng, H., Serio, M.A., Wójtowiez, M.A., Bassilakis, R., Solomon, P.R.: Reprocessing of Used Tires into Activated Carbon and Other Products. Ind. Eng. Chem. Res. 34, 3102-3111 (1995). 
https://doi.org/10.1021/ie00048a023

26. Danon, B., Görgens, J.: Determining rubber composition of waste tyres using devolatilisation kinetics. Thermochim. Acta. 621, 56-60 (2015). https://doi.org/10.1016/j.tca.2015.10.008

27. White, J.E., Catallo, W.J., Legendre, B.L.: Biomass pyrolysis kinetics: A comparative critical review with relevant agricultural residue case studies. J. Anal. Appl. Pyrolysis. 91, 1-33 (2011). https://doi.org/10.1016/j.jaap.2011.01.004

28. Vyazovkin, S.: Isoconversional Kinetics of Thermally Stimulated Processes. Springer International Publishing (2015)

29. Fang, Q.R., Makal, T.A., Young, M.D., Zhou, H.C.: Recent advances in the study of mesoporous metal-organic frameworks. Comments Inorg. Chem. 31, 165-195 (2010). https://doi.org/10.1080/02603594.2010.520254

30. Czajczyńska, D., Krzyżyńska, R., Jouhara, H., Spencer, N.: Use of pyrolytic gas from waste tire as a fuel: A review. Energy. 134, 1121-1131 (2017). https://doi.org/10.1016/j.energy.2017.05.042

31. Arteaga-Pérez, L.E., Jiménez, R., Grob, N., Gómez, O., Romero, R., Ronsse, F.: Catalytic upgrading of biomass-derived vapors on carbon aerogel-supported Ni: Effect of temperature, metal cluster size and catalyst-to-biomass ratio. Fuel Process. Technol. 178, 251-261 (2018). https://doi.org/10.1016/j.fuproc.2018.05.036

32. He, J., Lu, X.H., Shen, Y., Jing, R., Nie, R.F., Zhou, D., Xia, Q.H.: Highly selective hydrogenation of phenol to cyclohexanol over nano silica supported Ni catalysts in aqueous medium. Mol. Catal. 440, 87-95 (2017). https://doi.org/10.1016/j.mcat.2017.07.016

33. Graulis, S., Chateigner, D., Downs, R.T., Yokochi, A.F.T., Quirós, M., Lutterotti, L., Manakova, E., Butkus, J., Moeck, P., Le Bail, A.: Crystallography Open Database - An open-access collection of crystal structures. J. Appl. Crystallogr. 42, 726-729 (2009). https://doi.org/10.1107/S0021889809016690

34. Lah, B., Klinar, D., Likozar, B.: Pyrolysis of natural, butadiene, styrene-butadiene rubber and tyre components: Modelling kinetics and transport phenomena at different heating rates and formulations. 
Chem. Eng. Sci. 87, 1-13 (2013). https://doi.org/10.1016/j.ces.2012.10.003

35. Chen, J.H., Chen, K.S., Tong, L.Y.: On the pyrolysis kinetics of scrap automotive tires. J. Hazard. Mater. 84, 43-55 (2001). https://doi.org/10.1016/S0304-3894(01)00180-7

36. Quek, A., Balasubramanian, R.: An algorithm for the kinetics of tire pyrolysis under different heating rates. J. Hazard. Mater. 166, 126-132 (2009). https://doi.org/10.1016/j.jhazmat.2008.11.034

37. Pavia, D.L., Lampman, G.M., Kriz, G.S.: Introduction to Spectroscopy Pavia. Thomson Learning (2001)

38. Williams, P.T., Besler, S., Taylor, D.T.: The pyrolysis of scrap automotive tyres. The influence of temperature and heating rate on product composition. Fuel. 69, 1474-1482 (1990). https://doi.org/10.1016/0016-2361(90)90193-T

39. Fernández, A.M., Barriocanal, C., Alvarez, R.: Pyrolysis of a waste from the grinding of scrap tyres. J. Hazard. Mater. 203-204, 236-243 (2012). https://doi.org/10.1016/j.jhazmat.2011.12.014

40. Elbaba, I.F., Williams, P.T.: Two stage pyrolysis-catalytic gasification of waste tyres: Influence of process parameters. Appl. Catal. B Environ. 125, 136-143 (2012). https://doi.org/10.1016/j.apcatb.2012.05.020

41. Chen, R., Lun, L., Cong, K., Li, Q., Zhang, Y.: Insights into pyrolysis and co-pyrolysis of tobacco stalk and scrap tire: Thermochemical behaviors, kinetics, and evolved gas analysis. Energy. 183, 2534 (2019). https://doi.org/10.1016/j.energy.2019.06.127

42. Xu, F., Wang, B., Yang, D., Ming, X., Jiang, Y., Hao, J., Qiao, Y., Tian, Y.: TG-FTIR and PyGC/MS study on pyrolysis mechanism and products distribution of waste bicycle tire. Energy Convers. Manag. 175, 288-297 (2018). https://doi.org/10.1016/j.enconman.2018.09.013

43. Chen, R., Xu, X., Lu, S., Zhang, Y., Lo, S.: Pyrolysis study of waste phenolic fibre-reinforced plastic by thermogravimetry/Fourier transform infrared/mass spectrometry analysis. Energy Convers. Manag. 165, 555-566 (2018). https://doi.org/10.1016/j.enconman.2018.03.092

44. Chen, J., Ma, X., Yu, Z., Deng, T., Chen, X., Chen, L., Dai, M.: A study on catalytic co-pyrolysis of kitchen waste with tire waste over ZSM-5 using TG-FTIR and Py-GC/MS. Bioresour. Technol. 289, 
(2019). https://doi.org/10.1016/j.biortech.2019.121585

45. Wang, K., Zhong, Z., Zhang, B., Wang, J., Min, A., Ruan, R.: Catalytic pyrolysis of waste tire to produce valuable aromatic hydrocarbons : An analytical Py-GC / MS study. J. Anal. Appl. Pyrolysis. 122, 55-63 (2016). https://doi.org/10.1016/j.jaap.2016.10.023

46. Miguel, G.S., Aguado, J., Serrano, D.P., Escola, J.M.: Thermal and catalytic conversion of used tyre rubber and its polymeric constituents using Py-GC/MS. Appl. Catal. B Environ. 64, 209-219 (2006). https://doi.org/10.1016/j.apcatb.2005.12.004

47. Wang, J., Jiang, J., Wang, X., Liu, P., Li, J., Liu, G., Wang, K., Li, M., Zhong, Z., Xu, J., Ragauskas, A.J.: Catalytic conversion of rubber wastes to produce aromatic hydrocarbons over USY zeolites: Effect of SiO2/A12O3 mole ratio. Energy Convers. Manag. 197, (2019). https://doi.org/10.1016/j.enconman.2019.111857

48. Choi, G.G., Oh, S.J., Kim, J.S.: Scrap tire pyrolysis using a new type two-stage pyrolyzer: Effects of dolomite and olivine on producing a low-sulfur pyrolysis oil. Energy. 114, 457-464 (2016). https://doi.org/10.1016/j.energy.2016.08.020

49. Pan, Y., Yang, D., Sun, K., Wang, X., Zhou, Y., Huang, Q.: Pyrolytic transformation behavior of hydrocarbons and heteroatom compounds of scrap tire volatiles. Fuel. 276, (2020). https://doi.org/10.1016/j.fuel.2020.118095

50. Alvarez, J., Lopez, G., Amutio, M., Mkhize, N.M., Danon, B., van der Gryp, P., Görgens, J.F., Bilbao, J., Olazar, M.: Evaluation of the properties of tyre pyrolysis oils obtained in a conical spouted bed reactor. Energy. 128, 463-474 (2017). https://doi.org/10.1016/j.energy.2017.03.163

51. Singh, R.K., Ruj, B., Jana, A., Mondal, S., Jana, B., Sadhukhan, A.K., Gupta, P.: Pyrolysis of three different categories of automotive tyre wastes: Product yield analysis and characterization. J. Anal. Appl. Pyrolysis. 135, 379-389 (2018)

52. Williams, P.T.: Pyrolysis of waste tyres: A review. Waste Manag. 33, 1714-1728 (2013). https://doi.org/10.1016/j.wasman.2013.05.003

53. Williams, P.T., Besler, S.: Pyrolysis-thermogravimetric analysis of tyres and tyre components. Fuel. 
74, 1277-1283 (1995)

54. Olazar, M., Aguado, R., Arabiourrutia, M., Lopez, G., Barona, A., Bilbao, J.: Catalyst effect on the composition of tire pyrolysis products. Energy and Fuels. 22, 2909-2916 (2008).

https://doi.org/10.1021/ef8002153

55. Corma Canos, A., Iborra, S., Velty, A.: Chemical routes for the transformation of biomass into chemicals. Chem. Rev. 107, 2411-2502 (2007). https://doi.org/10.1021/cr050989d

56. Busca, G.: Metal Catalysts for Hydrogenations and Dehydrogenations. In: Heterogeneous Catalytic Materials. pp. 297-343 (2014)

57. Pyle, D.L., Zaror, C.A.: Heat transfer and kinetics in the low temperature pyrolysis of solids. Chem. Eng. Sci. 39, 147-158 (1984). https://doi.org/10.1016/0009-2509(84)80140-2 
Figures

(a)

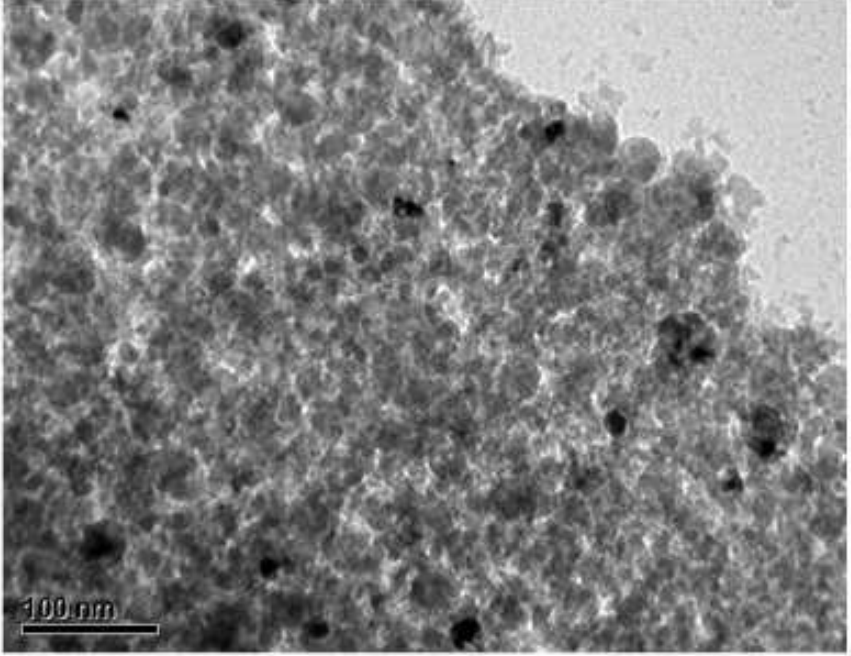

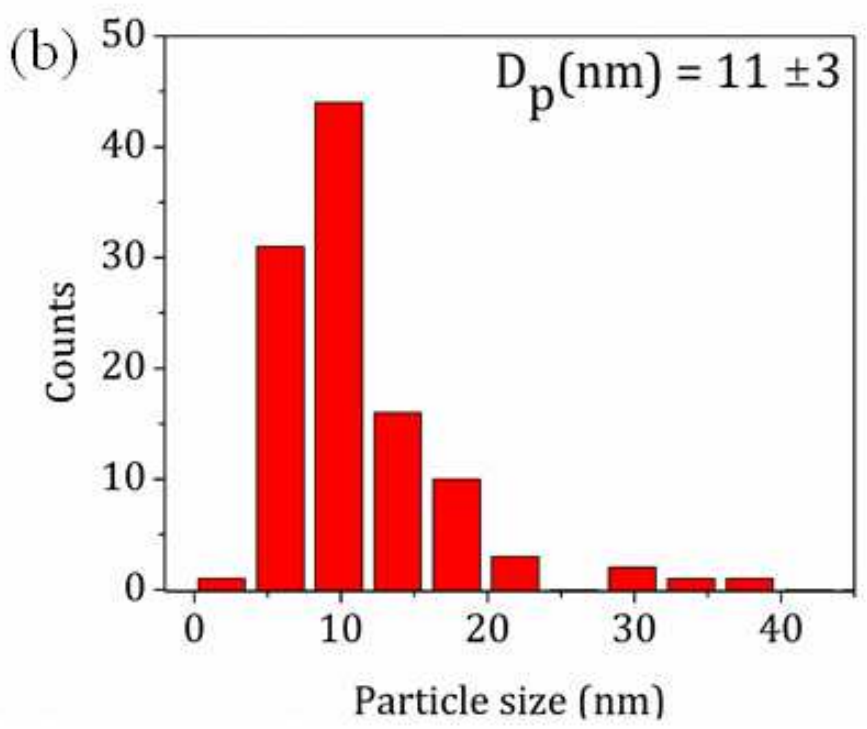

Figure 1

a) TEM image and b) Particle size distribution, average particle size (Dp), and standard deviation for $\mathrm{Ni} / \mathrm{SiO} 2$ catalyst. The bar in the images represents $100 \mathrm{~nm}$.

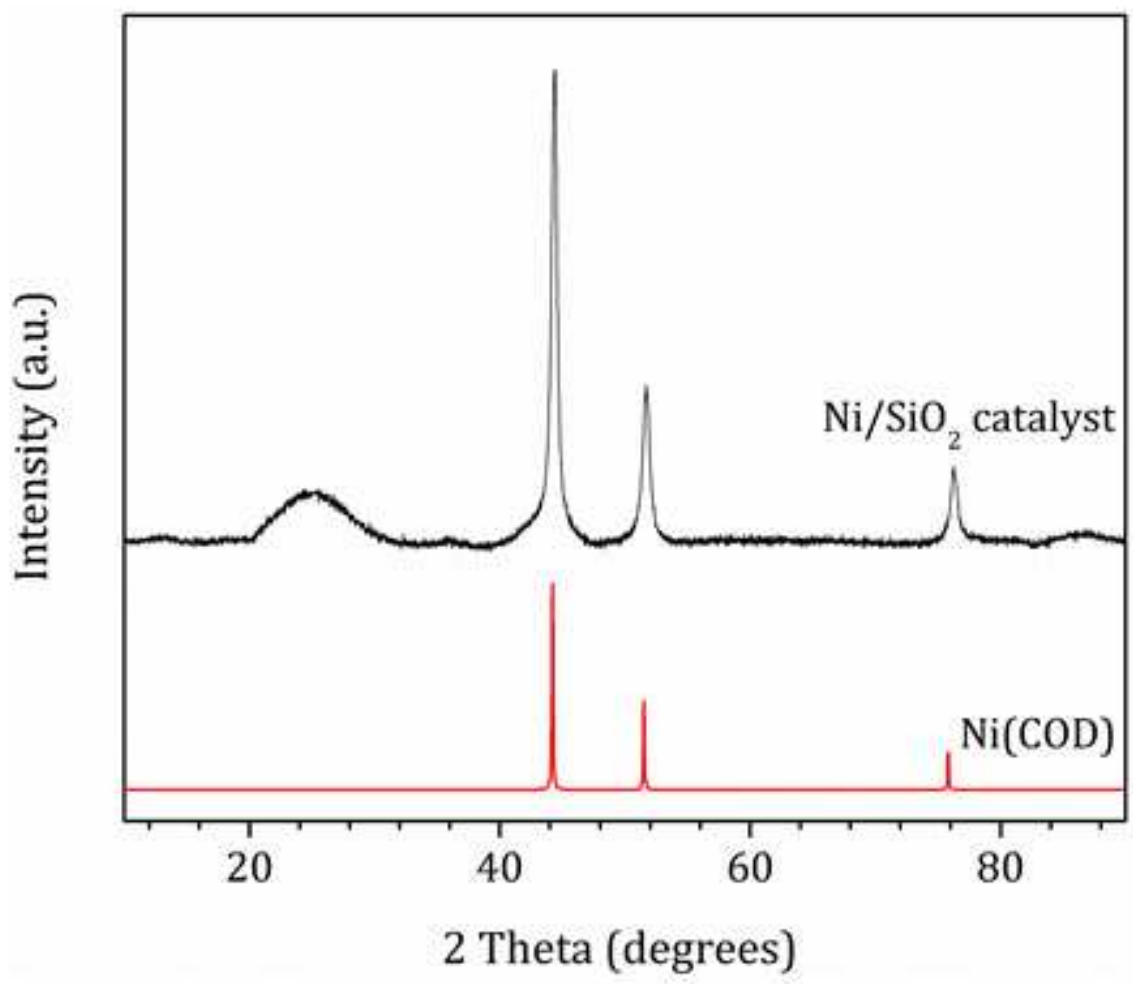

Figure 2 
XRD results of fresh Ni catalyst sample. Standards from the COD database [29] : Ni (2100637). (http://www.crystallography.net/cod/).

(a)

(b)
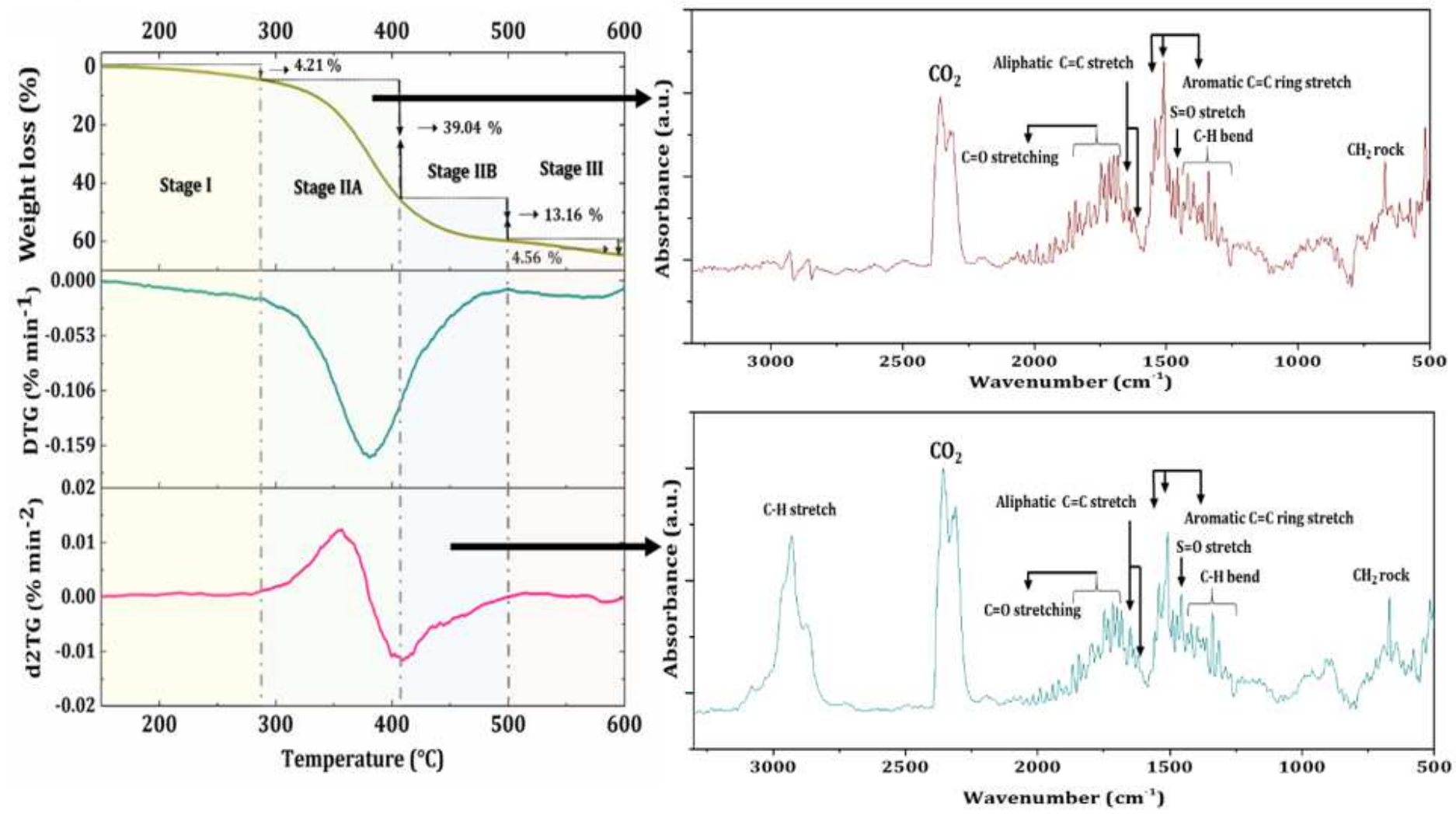

Figure 3

(a) Thermogravimetric analyses (TGA) and its first and second derivate for non-catalytic waste tire decomposition and (b) FTIR spectra of evolved gas 
(a)

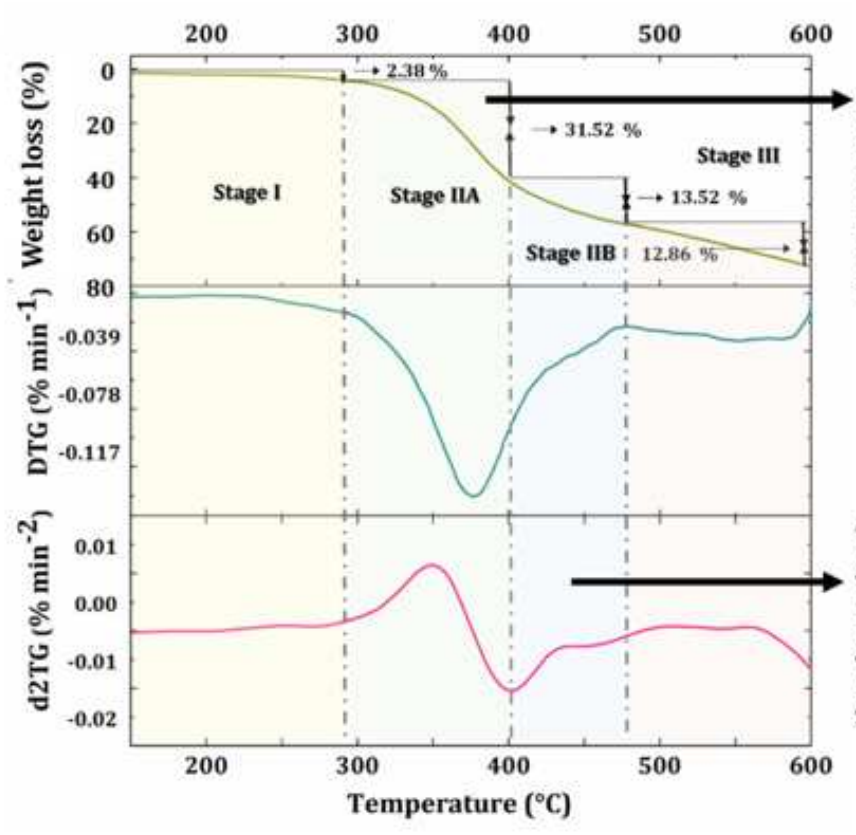

(b)
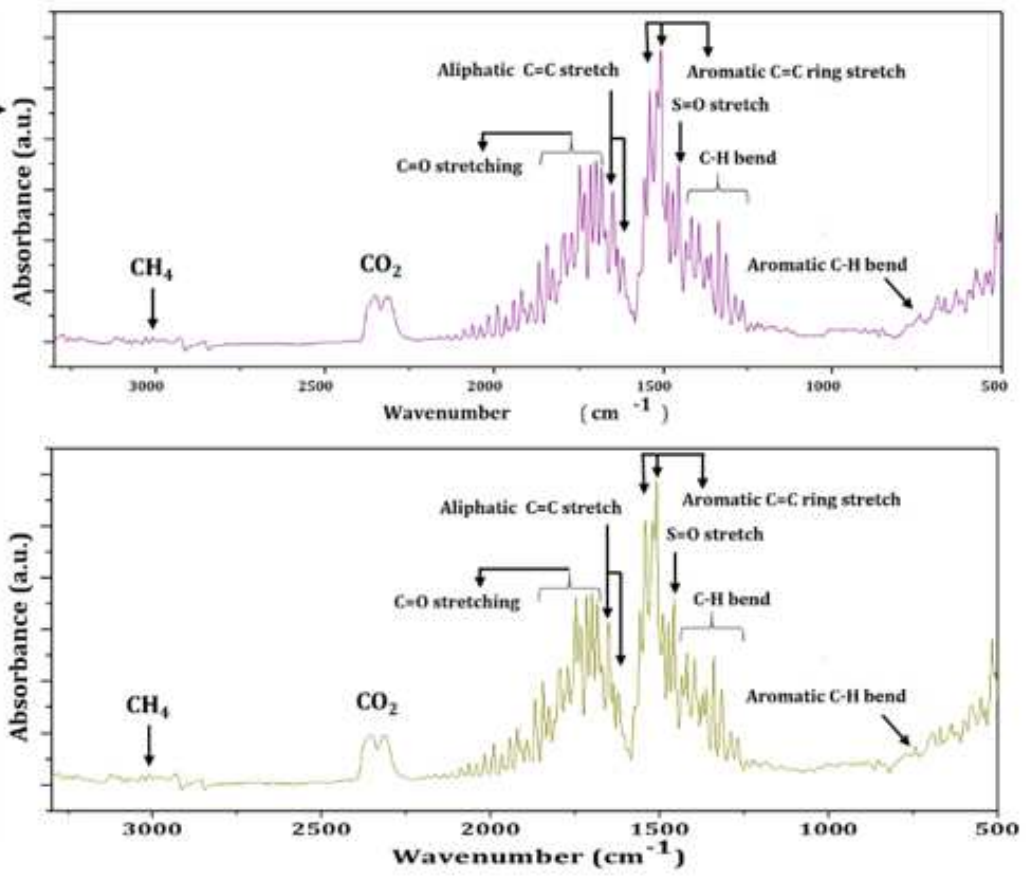

Figure 4

Thermogravimetric analyses (TGA) and its first and second derivate for catalytic waste tire decomposition and (b) FTIR spectra of evolved gas in the presence of $\mathrm{Ni} / \mathrm{SiO} 2$ catalyst. 
(a)

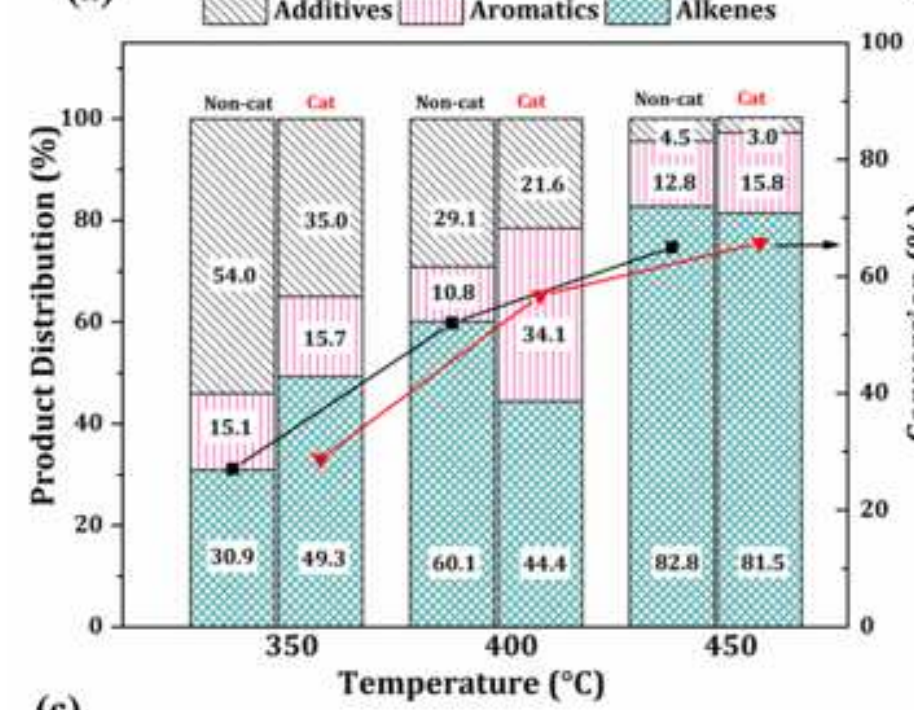

(c)

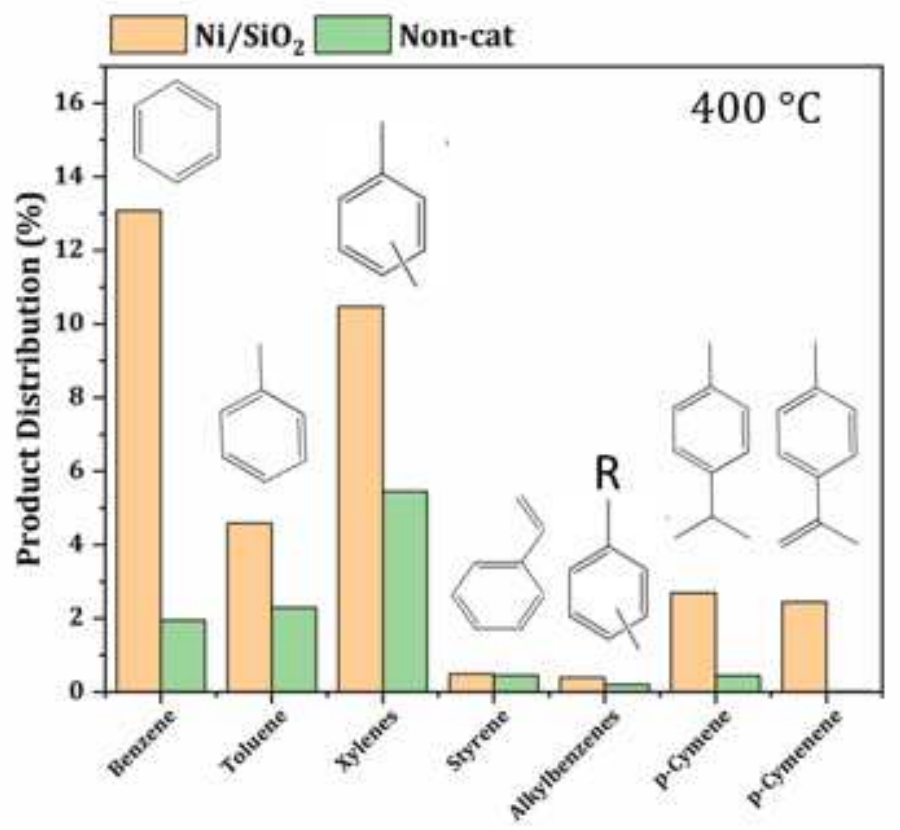

(b)

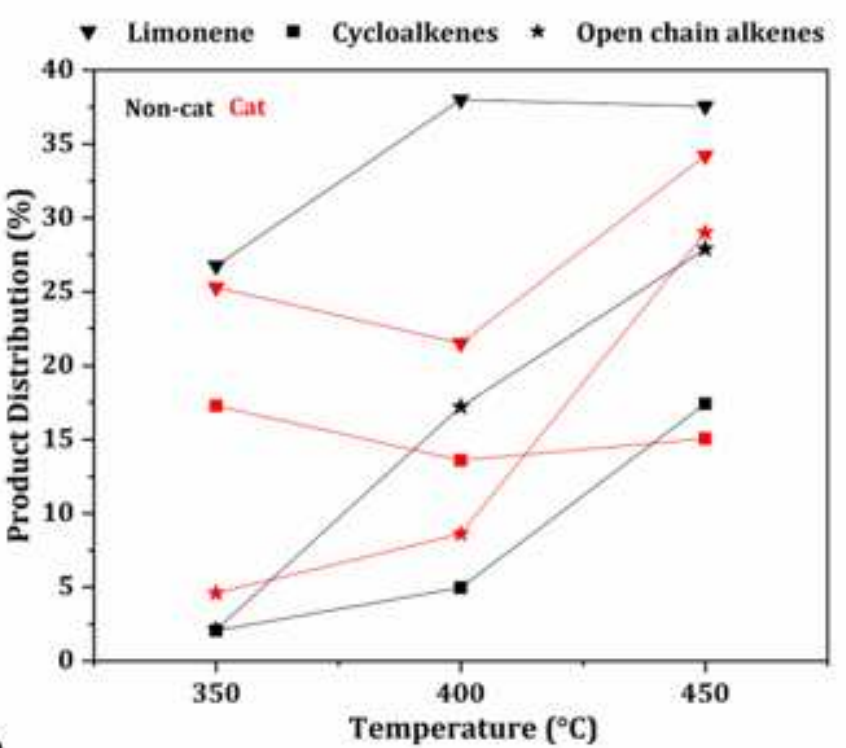

(d)

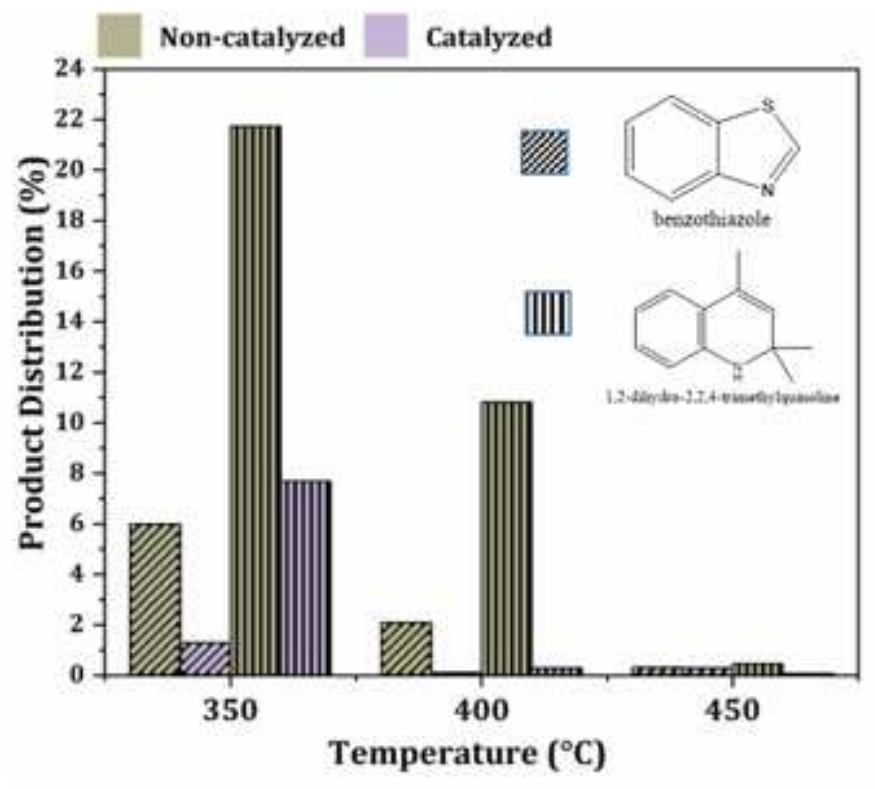

Figure 5

Effect of temperature and use of Ni catalyst on (a) product distribution (b) limonene and alkenes content, (c) monoaromatics content, and (d) $\mathrm{N}$ - and S-compounds content, during waste tire pyrolysis. 


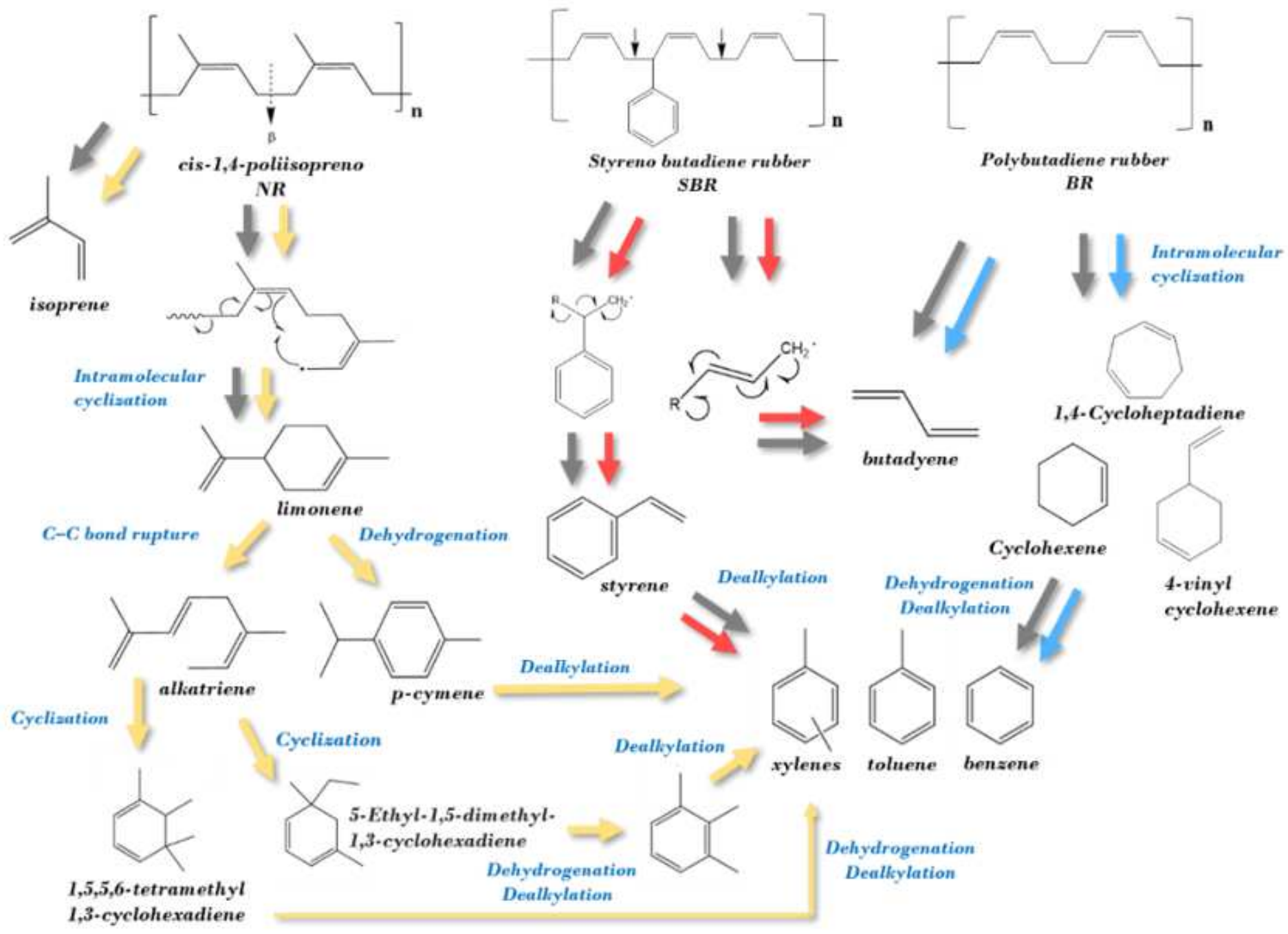

Figure 6

Suggested reaction pathways of waste tire pyrolysis carried out with or without catalyst. Ni/SiO2 catalyst: colored arrows (light yellow:NR, red:SBR, blue:BR), uncatalyzed reaction: gray arrows. 

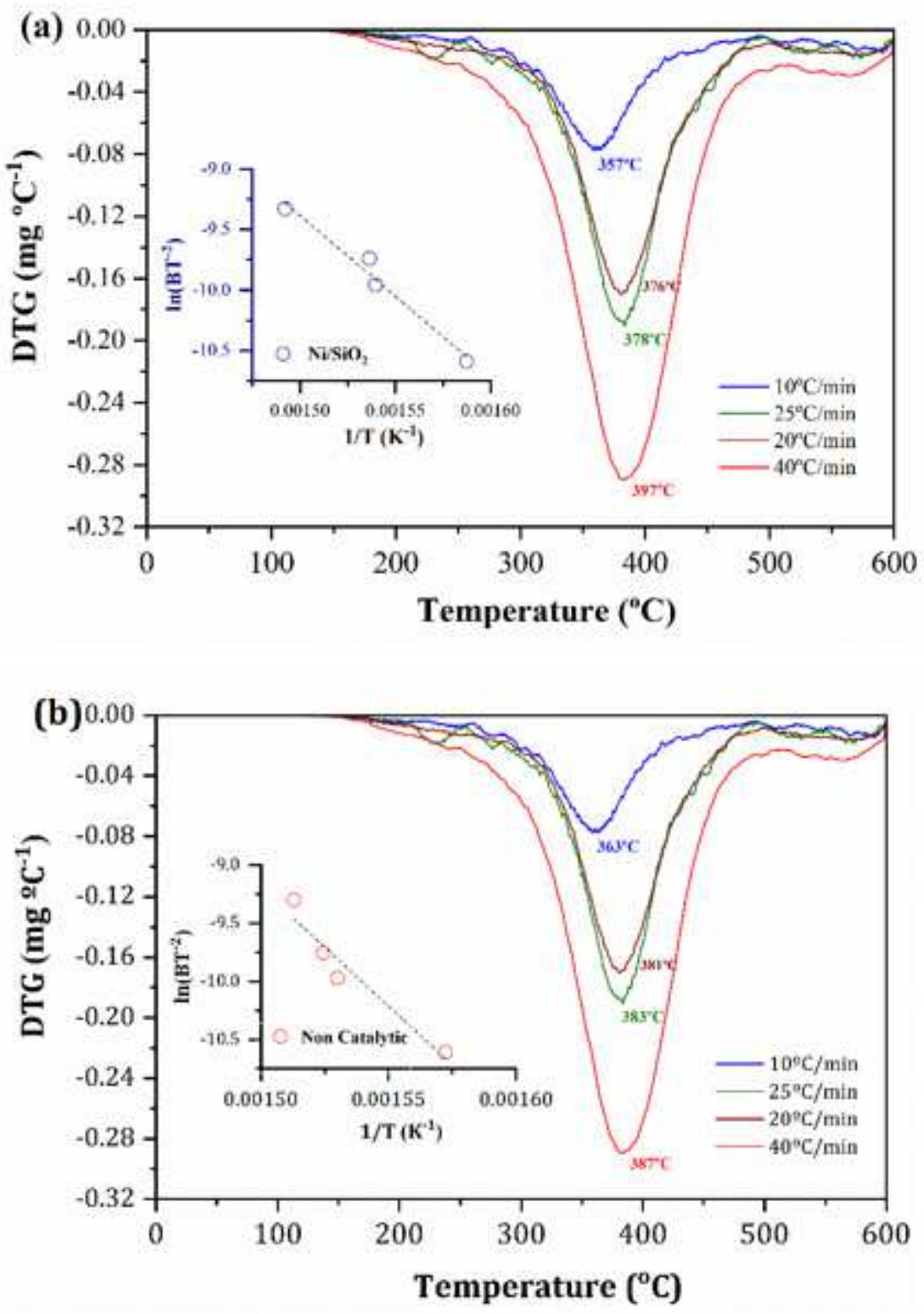

Figure 7

DTG curves for WTs at different heating rates $\left(\beta=10,20,25,40^{\circ} \mathrm{C}\right.$ min-1) with (a) Ni/SiO2 catalyst and (b) under non-catalytic conditions. The insert shows the KAS kinetic model curve. 


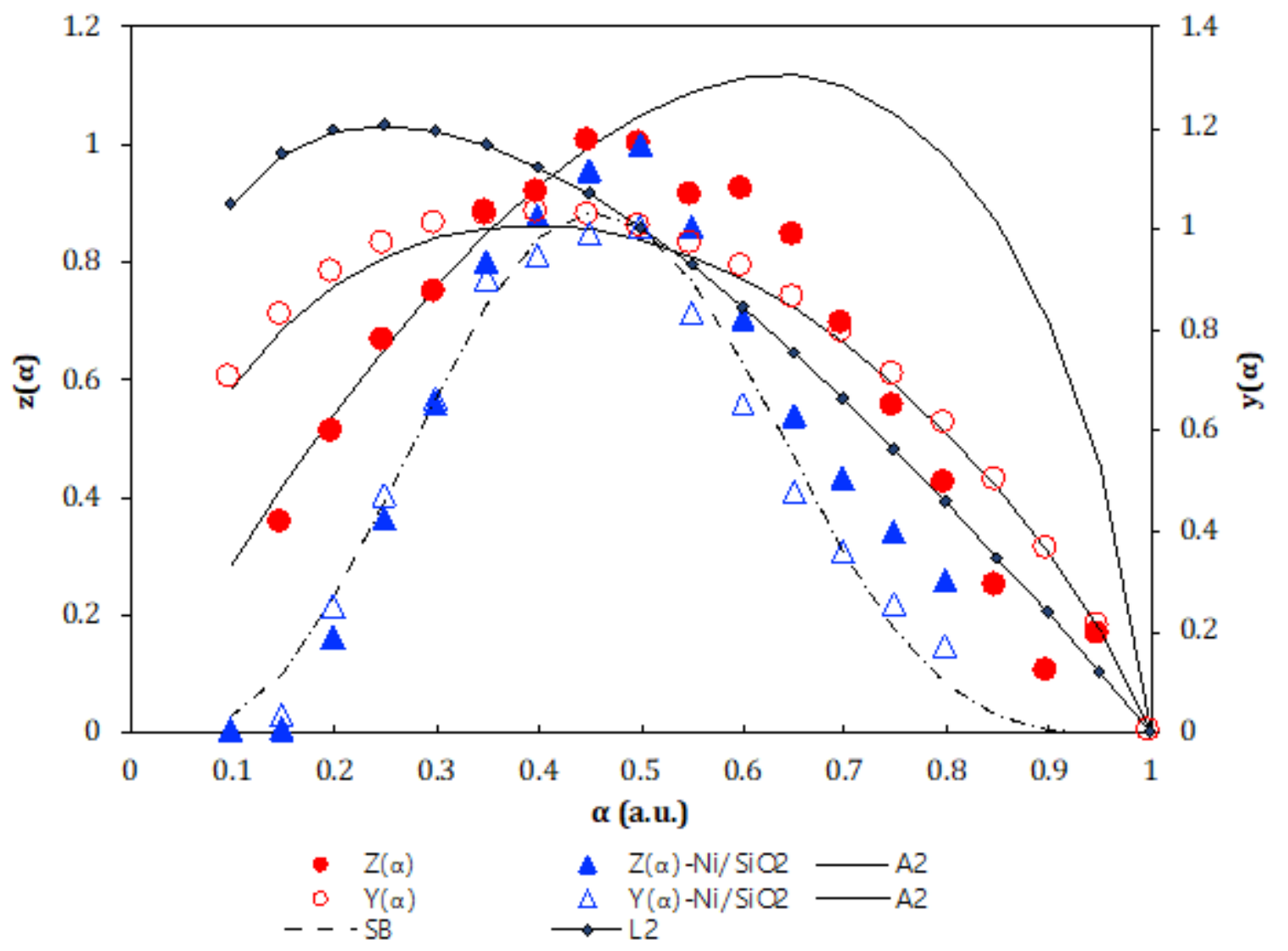

Figure 8

Elucidation of reaction models by the $z(a)$-plot and $y(a)$-plot. Continuous lines represent the theoretical models. The empty and filled markers refer to experimental $z(a)$ and $y(a)$, respectively.

\section{Supplementary Files}

This is a list of supplementary files associated with this preprint. Click to download.

- GraphicalAbstractWBV.docx

- SupplementaryInformationWBVRev.docx 